\section{A PROPOSED METHODOLOGY FOR RATING AIR-SOURCE HEAT PUMPS THAT HEAT, COOL, AND PROVIDE DOMESTIC WATER HEATING}

\section{Brian P. Dougherty}

U.S. DEPARTMENT OF COMMERCE Natlonal Institute of Standards and Technology

National Englneering Laboratory Conter for Bullding Technology Bullding Environment Division Galthersburg, MD 20899
U.S. DEPARTMENT OF COMMERCE Robert A. Mosbacher, Secretary MATIONAL INSTIUTE OF STANDARDS AND TECHNOLOQY

Raymond Q. Kammer, Acting Director 

Brian P. Dougherty

U.S. DEPARTMENT OF COMMERCE National Institute of Standards and Technology Natlonal Englneering Laboratory Center for Bullding Tochnology Bullding Environmont Division Galthersburg, MD 20899

Prepared for: Elcetric Power Research Institute Palo Nto, Callfomla 94304 John P. Kesselring, Project Manager

U.S. Department of Energy Washington, DC 20585

August 1989

EPRI RP2033-26

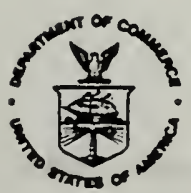

U.S. DEPARTMENT OF COMMERCE Robert A. Mosbacher, Secretary MATIONAL INSTITUTE OF STANDARDS AND TECHNOLOAY

Raymond Q. Kammer, Acting Director 

A PROPOSED METHODOLOGY FOR RATING AIR-SOURCE HEAT PUMPS THAT HEAT, COOL, AND PROVIDE DOMESTIC WATER HEATING

\begin{abstract}
At the National Institute of Standards and Technology (NIST), work is on-going to develop a proposed procedure for testing and rating air-source heat pumps that heat, cool, and provide domestic water heating. The family of appliances providing these three functions are referred to here as integrated (or combined) heat pump/water heating appliances. For these appliances, the heat pump contributes to heating the water in a storagetype water heater through the use of a refrigerant-to-potable water heat exchanger.
\end{abstract}

The work at NIST has centered upon developing a proposed rating methodology for integrated appliances that heat water in a water heating only mode or while simultaneously air-conditioning or space heating. Despite the emphasis, the proposed methodology provides a framework for rating other types of integrated heat pump/water heating appliances.

The laboratory testing, the calculation procedure, and the method for reporting performance are described. The testing is an adaption of the laboratory tests conducted when rating conventional heat pumps and water heaters. Seasonal estimates of energy consumption rates are calculated using a bin type approach. Combined performance factors and operating costs are used for reporting performance.

Key Words: rating methodology, integrated appliance, heat pump, space heating, air conditioning, water heating, seasonal performance. 



\section{METRIC CONVERSION FACTORS}

In view of the presently accepted practice of the building industry in the United States, common U.S. units of measurements are used in this report. In recognition of the United States as a signatory to the General Conference of Weights and Measures, which gave official status to the SI system of units in 1960, appropriate conversion factors are provided in the table below. The reader interested in making further use of the coherent system of SI units is referred to: NBS SP330, 1972 Edition, "The International System of Units," or E380-72, ASTM Metric Practice Guide (American National Standard 2210.1).

\section{METRIC CONVERSION FACTORS}

$\begin{array}{ll}\text { Length } & 1 \text { inch }(\mathrm{in})=25.4 \text { millimeters (mm) } \\ & 1 \text { foot }(\mathrm{ft})=0.3048 \text { meters (m) } \\ \text { Area } & 1 \mathrm{ft}^{2}=0.092903 \mathrm{~m}^{2} \\ \text { Volume } & 1 \mathrm{ft}^{3}=0.028317 \mathrm{~m}^{3} \\ & 1 \mathrm{gallon}=0.0037854 \mathrm{~m}^{3} \\ \text { Temperature } & { }^{\circ} \mathrm{F}=9 / 5^{\circ} \mathrm{C}+32 \\ \text { Temperature } & 1{ }^{\circ} \mathrm{F}=5 / 9^{\circ} \mathrm{C} \text { or } \mathrm{K} \\ \text { Interval } & 1 \mathrm{pound}(\mathrm{lb})=0.453592 \mathrm{kilograms}(\mathrm{kg}) \\ \text { Mass } & 1 \mathrm{lb} / \mathrm{ft}=16.0185 \mathrm{~kg} / \mathrm{m}^{3} \\ \text { Mass per Unit } & 1 . \mathrm{Btu}=1.05506 \mathrm{kilojoules}(\mathrm{kJ}) \\ \text { Volume } & 1 \mathrm{Btu} / \mathrm{lb} \cdot{ }^{\circ} \mathrm{F}=4.1868 \mathrm{~kJ} / \mathrm{kg} \cdot \mathrm{K} \\ \text { Energy } & \end{array}$


TABLE OF CONTENTS . . . . . . . . . . . . . . . . . . . . . . . iv

LIST OF TABLES . . . . . . . . . . . . . . . . . . . . . . . vi

IIST OF FIGURES. . . . . . . . . . . . . . . . . . . . . . . . . . vii

NOMENCLATURE . . . . . . . . . . . . . . . . . . . . . . viii

1. INTRODUCTION. . . . . . . . . . . . . . . . . . 1

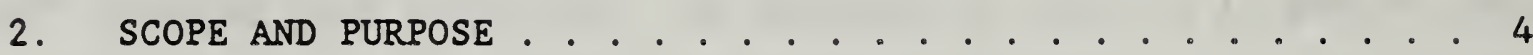

3. APPLIANCE DESCRIPTION . . . . . . . . . . . . . . 5

3.1 Generic Description. . . . . . . . . . . . . . . . . . 5

3.2 Appliances Covered by the Proposed Methodology . . . . . 7

4. PROPOSED METHODOLOGY: AN OVERVIEW. . . . . . . . . . . . 8

5. LABORATORY TESTING. . . . . . . . . . . . . . . . 11

5.1 Recovery Test: General Description . . . . . . . . . 11

5.2 Recovery Test: Proposed Testing Conditions . . . . . . 13

5.3 Capacity and Power Usage Tests . . . . . . . . . . . 18

5.3.1 Proposed Test Conditions . . . . . . . . . . . . 18

5.3.2 Frost Accumulation Test: Water-source . . . . 21

5.4 Deriving Bin Performance Data . . . . . . . . . . . . . 23

5.4.1 Steady-state Data: Emphasis on
Variable-speed Units....... 23

5.4.2 Frosting and Defrosting Effects......... 26

6. CALCULATION PROCEDURE. . . . . . . . . . . . . . . 34

6.1 Space Cooling Season. . . . . . . . . . . . . 36

6.1.1 Load Factor Calculations: Water Heating Begins in a Combined Mode. . . . . . . . . 40

6.1.2 Load Factor Calculations: Water Heating Begins in a Water Heating Only Mode. . . . . . 42

6.1.3 Calculation of Energy Consumption Rates. . . . . 44

6.2 Space Heating Season. . . . . . . . . . . . . . 47 
7. METHOD FOR REPORTING PERFORMANCE . . . . . . . . . . 50

7.1 Combined Performance Factors. . . . . . . . . . . 51

7.2 Operating Costs . . . . . . . . . . . 56

8. ACKNOWLEDGEMENTS .................... 62

9. REFERENCES .................. . . 63

10. APPENDIX A Load Factor Calculations: Additional calculation sequences for sub-bins where water heating begins in a water heating only mode. . . . . 66

11. APPENDIX B Derivation of equations for determining the length of the space conditioning seasons... 69 
1. Typical Residential Usage of Hot Water/Task . . . . . . . . 73

2. Summary of Proposed Test Conditions for Rating Variable-speed, Integrated Heat Pump/Water Heating Appliances During the Space Cooling Season. . . . . . . . . 74

3. Summary of Proposed Test Conditions for Rating Variable-speed, Integrated Heat Pump/Water Heating Appliances During the Space. Heating Season.

4. Summary of Proposed Test Conditions for Rating Single-speed, Integrated Heat Pump/Water Heating Appliances During the Space Cooling Season. . . . . . . . 76

5. Summary of Proposed Test Conditions for Rating Single-speed, Integrated Heat Pump/Water Heating Appliances During the Space Heating Season. . . . . . . . . . 77

6. Standby Losses of an Electric Water Heater as a Function of Its Energy Factor. . . . . . . . . . . . . . . . 78

7. Bin Calculation Worksheet for an Integrated HP/WH Appliance During the Space Cooling Season... . . . . . . . . . 79

8. Bin Calculation Worksheet for an Integrated HP/WH Appliance During the Space Heating Season . . . . . . . . . . . . 81

9. Bin Calculation Worksheet for the Space Cooling Only Mode -- Used to Determine Conventional SEER . . . . . . . . 83

10. Length of Operating Seasons Based on Established Cooling . . 84 Load Hours and Heating Load Hours for Different Climatic Regions

11. Bin Calculation Worksheet for an Integrated HP/WH Appliance During a Water Heating Only Season. 


\section{LIST OF FIGURES}

PAGE

1. Components of an integrated heat pump/water heating appliance

2. Recovery Test Results: Percentage contribution of the water heater resistive elements or fossil-fuel burner (auxiliary heat) versus the water heating capacity of the integrated appliance.

3. Space cooling only mode: (a) capacity and building load (b) power usage .................... 88

4. Space cooling only mode: energy efficiency ratio (EER) interpolation for the intermediate-speed operating range. .

5. Combined space cooling and water heating mode: (a) space cooling capacity and building load (b) power usage. . . . . 90

6. Combined space cooling and water heating mode: water heating capacity of the integrated appliance . . . . . . . . . . 91

7. Water heating only mode: (a) capacity (b) power usage. . . 92 
ACPF = annual combined performance factor; the dimensional equivalent of the coefficient of performance of an integrated heat pump/water heating appliance in meeting the annual space conditioning and water heating loads for a specific climatic region, $(B t u / W \cdot h)$

ASCL = annual space cooling load, (Btu)

ASHL = annual space heating load, (Btu)

AWHL = annual water heating load, (Btu)

BL = building load, $(\mathrm{Btu} / \mathrm{h})$

C $=0.77$, an experience factor which improves the agreement between the measured and calculated building load, dimensionless

$\mathrm{C}_{\mathrm{D}} \quad=$ cyclic degradation factor, dimensionless

$\mathrm{C}_{\mathrm{p}} \quad=$ specific heat, $\left(\mathrm{Btu} / \mathrm{lb} \cdot{ }^{\circ} \mathrm{F}\right)$

CLH = cooling load hours; for a given geographical location, the number of hours required to meet the annual building cooling load $\left(65^{\circ} \mathrm{F}\right.$ base) if the heat pump cooling capacity was constant and equal to its capacity at the design outdoor temperature and, if applicable, maximum compressor speed; CLH account for the 1.1 heat pump oversizing factor at design conditions, (h)

COP $=$ coefficient of performance, dimensionless

CPF = combined performance factor; the dimensional equivalent to the coefficient of performance of the integrated heat pump/water heating appliance in meeting the seasonal space conditioning and water heating loads, $(B t u / w \cdot h)$

$\mathrm{CR} \quad=$ capacity ratio; used for correcting capacity data based on the results of the frost accumulation test; defined in equation 11 , dimensionless

$\mathrm{CSH}=$ cooling season hours; the total number of hours in the space cooling and water heating season; directly related to cooling load hours (see equation 64), (h)

DHR = design heating requirement; used in the calculation of the space heating building load, (Btu/h)

e = energy consumption rate of the integrated appliance, water heater, or electric resistance space heater, (W) 
$\mathrm{E} \quad=$ energy used by the integrated appliance, heat pump, or water heater, $(\mathrm{W} \cdot \mathrm{h})$

$\dot{E} \quad=$ average electrical power usage during steady-state operation, including frosting/defrosting effects if applicable, (W)

$E_{\mathrm{aux}}=$ electrical energy used by the controls and blower of an oil or gas-fired water heater during a 24-hour simulated use test, $(W \cdot h)$

$E_{f} \quad=$ water heater energy factor; the water heating efficiency (or coefficient of performance) of a conventional storage-type water heater, dimensionless

EER = energy efficiency ratio; the dimensional equivalent to the coefficient of performance while operating in a space cooling only mode at a specific outdoor temperature, indoor temperature, and compressor speed, $(B t u / w \cdot h)$

HLH = heating load hours; for a given geographical location, the number of hours required to meet the annual building heating load $\left(65^{\circ} \mathrm{F}\right.$ base) if the heat pump heating capacity was constant; heating capacity is defined in terms of the design heating requirement, (h)

$\mathrm{HSH}=$ heating season hours; the total number of hours in the space heating and water heating season; directly related to heating load hours (see equation 62), (h)

HSPF = heating seasonal performance factor; the dimensional equivalent of the seasonal coefficient of performance of a heat pump or integrated appliance in meeting the annual space heating load while operating in a space heating only mode, $(B t u / w \cdot h)$

ISH = in-between season hours; the total number of hours in the season where no space conditioning occurs, only water heating, (h)

m = fractional sub-bin hours; used in the bin calculations to determine the operating times in each mode, dimensionless

$\mathrm{n}=$ fractional bin hours; the fraction of the total hours in a season that the hourly-averaged outdoor temperature falls within each $5^{\circ} \mathrm{F}$ temperature bin, dimensionless

$\mathrm{N}=$ total number of $5^{\circ} \mathrm{F}$ outdoor temperature bins; for the cooling season, $\mathrm{N}$ equals eight; for the heating season, $\mathrm{N}$ depends upon the climatic region, dimensionless

PLF = part load factor; used in correcting for performance degradation due to cycling of the unit, dimensionless 
PR = power usage ratio; used for correcting power usage data based on the results from the frost accumulation test; defined in equation 12 , dimensionless

q = weighted loads, either space conditioning or water heating, for each temperature bin; the building load and water heating load are "weighted" using the fractional bin hours assigned to each bin, $(B t u / h)$

Q = the energy content of the building or water heating loads, (Btu)

Q = average capacity during steady-state operation of the integrated appliance, including frosting/defrosting effects if applicable; also, rate of heat transfer, (Btu/h)

Q ev,fx = the energy transferred from the outdoor air to the refrigerant in the outdoor coil (evaporator) during the frosting period of a frost accumulation test, (Btu)

$Q_{w, d f}=$ the energy removed from the domestic hot water during the defrost cycle of a water-source frost accumulation test, (Btu)

SEER = seasonal energy efficiency ratio; the dimensional equivalent of the seasonal coefficient of performance of a heat pump or integrated appliance in meeting the annual space cooling load while operating in a space cooling only mode, $(B t u / w \cdot h)$

$t \quad=$ time, $(\mathrm{hr})$

$\mathrm{T} \quad=$ temperature, $\left({ }^{\circ} \mathrm{F}\right)$

$\mathrm{T}_{\mathrm{m}}=$ the water main temperature; the temperature of the water supplied to the water heater during a draw, $\left({ }^{\circ} \mathrm{F}\right)$

$\mathrm{T}_{0} \quad=$ space cooling only mode: outdoor temperature where the building load equals the space cooling capacity of the unit while operating at the compressor speed prescribed for the intermediate-speed test, ( $\left.{ }^{\circ} \mathrm{F}\right)$

$\mathrm{T}_{1} \quad=$ space cooling only mode: outdoor temperature where the building load equals the space cooling capacity of the unit while operating at minimum compressor speed, $\left({ }^{\circ} \mathrm{F}\right)$

$\mathrm{T}_{1}^{\prime} \quad=$ combined space cooling and full condensing water heating mode: outdoor temperature where the building load equals the space cooling capacity of the unit while operating at minimum compressor speed (and a representative inlet water temperature and flow rate to the refrigerant-to-water heat exchanger), $\left({ }^{\circ} \mathrm{F}\right)$ 


\begin{tabular}{|c|c|c|}
\hline $\mathrm{T}_{1}$ & $=$ & $\begin{array}{l}\text { combined space cooling and desuperheating water heating mode: } \\
\text { outdoor temperature where the building load equals the space } \\
\text { cooling capacity of the unit while operating at minimum } \\
\text { compressor speed (and a representative inlet water temperature } \\
\text { and flow rate to the refrigerant-to-water heat exchanger), }\left({ }^{\circ} \mathrm{F}\right)\end{array}$ \\
\hline $\mathrm{T}_{2}$ & $=$ & $\begin{array}{l}\text { space cooling only mode: outdoor temperature where the } \\
\text { building load equals the space cooling capacity of the unit } \\
\text { while operating at maximum compressor speed, }\left({ }^{\circ} \mathrm{F}\right)\end{array}$ \\
\hline$x_{2}^{\prime}$ & $=$ & $\begin{array}{l}\text { combined space cooling and full } 1 \text { condensing water heating mode: } \\
\text { outdoor temperature where the building load equals the space } \\
\text { cooling capacity of the unit while operating at maximum } \\
\text { compressor speed (and a representative inlet water temperature } \\
\text { and flow rate to the refrigerant-to-water heat exchanger }),\left({ }^{\circ} \mathrm{F}\right)\end{array}$ \\
\hline $\mathrm{T}_{2}^{\prime \prime}$ & $=$ & $\begin{array}{l}\text { combined space cooling and desuperheating water heating mode: } \\
\text { outdoor temperature where the building load equals the space } \\
\text { cooling capacity of the unit while operating at maximum } \\
\text { compressor speed (and a representative inlet water temperature } \\
\text { and flow rate to the refrigerant-to-water heat exchanger), }\left({ }^{\circ} \mathrm{F}\right)\end{array}$ \\
\hline $\mathrm{v}$ & $=$ & volume, (gal) \\
\hline WL & $=$ & water heating load, $(\mathrm{Btu} / \mathrm{h})$ \\
\hline $\mathrm{x}$ & $=$ & $\begin{array}{l}\text { load factor (the percentage of time that the appliance is } \\
\text { operating), dimensionless }\end{array}$ \\
\hline$\delta$ & $=$ & heat pump low temperature cut-off factor, dimensionless \\
\hline$\eta_{\mathrm{R}}$ & $=$ & recovery efficiency of the water heater, dimensionless \\
\hline & $=$ & density, (lbm/gal) \\
\hline
\end{tabular}

\section{Subscripts}

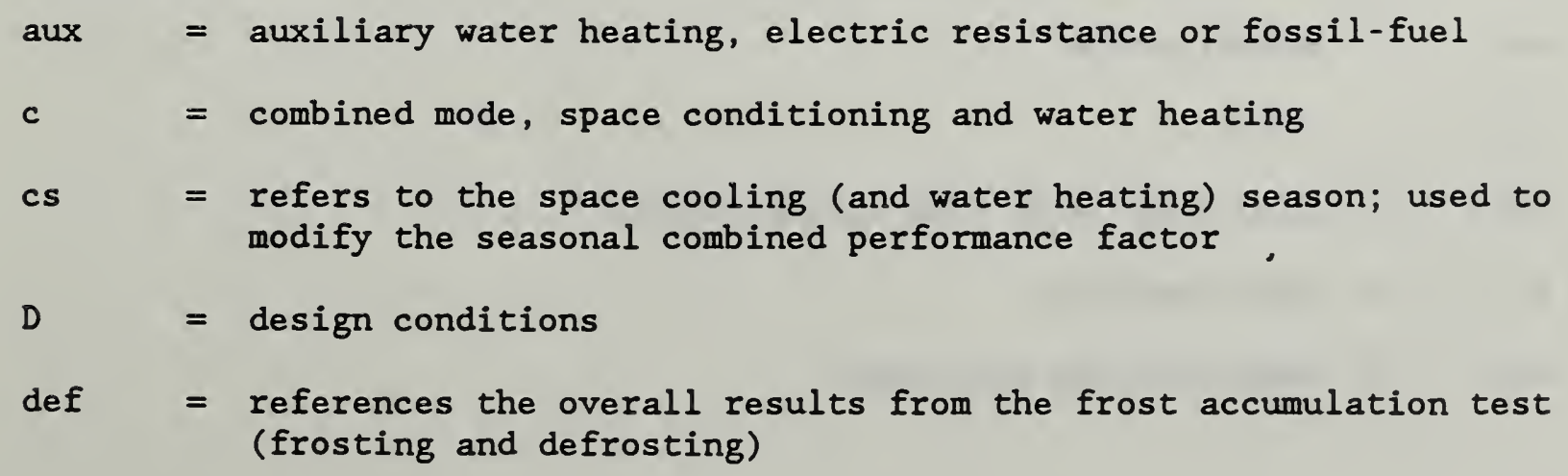





\section{INTRODUCTION}

A standard procedure does not exist for estimating the seasonal operating costs and seasonal coefficients of performance (COP) for heat pumps that heat, cool, and provide domestic water heating, hereafter called integrated heat pump/water heating (HP/WH) appliances. The existing testing and rating procedures for conventional heat pumps [1-5] and storage-type water heaters [6-7] cannot be used in tandem to estimate seasonal costs and COP's because space conditioning and water heating are interdependent functions for an integrated $\mathrm{HP} / \mathrm{WH}$ appliance.

In an effort to contribute to the development of a suitable standard, work is on-going at the National Institute of Standards and Technology (NIST). The NIST work has thus far progressed while giving emphasis to a specific type of integrated appliance. The two key distinguishing features of the appliance type considered are that it can operate in a water heating only mode and that it gives priority to space conditioning over heating water. Despite the emphasis, many of the issues addressed and recommendations made in the proposed methodology are applicable to rating other types of integrated $\mathrm{HP} / \mathrm{WH}$ appliances, including heat pumps having a desuperheater.

In general, the NIST proposed methodology is an adaptation of the existing testing and rating procedures for heat pumps [1-5] and water heaters [6-7]. For example, the laboratory tests are variations of those tests required for rating the separate appliances. Seasonal estimates of energy consumption rates are calculated using a temperature bin approach which is similar to, although more complex than, the calculation procedure used for heat pumps. Seasonal and annual operating costs and performance 
factors (COP's expressed in units of $B t u / W \cdot h$ ) are used to show the relative performance of the integrated appliance. Notably, a complication arises when making seasonal cost calculations using heat pump cooling and heating load hours [1-5]. One alternative for handling the complication is discussed.

The proposed methodology attempts to address as completely as possible all aspects of testing and rating air-source, integrated HP/WH appliances having up to six operating modes, one being a water heating only mode, and having either single or variable-speed components.

Specific issues that are addressed include how to report performance, how to account for water-source defrost, and how to determine the water heating contributed by the integrated appliance versus the water heater resistive elements or fossil-fuel burner. With regard to the first issue, the reporting of seasonal and/or annual combined space conditioning and water heating performance factors is recommended by NIST. The second issue relates to appliances that use the refrigerant-to-water heat exchanger, rather than the indoor coil, as the evaporator during a defrost cycle. The last issue stems from the fact that many variables affect the water heating contribution of the integrated appliance (e.g., coincidence between the draws occurring and the heat pump operating, the size of the water heater, the hot water draw schedule, the daily hot water usage, the water main temperature, the tank thermostat setting(s), the controls of the unit, and the water heating capacity of the integrated appliance), but only a bare minimum of system variable combinations can be addressed by the laboratory tests and the calculation procedure. 
In addition to NIST, various other groups have and continue to contribute to the development of a standard approach for rating air-source integrated HP/WH appliances. Cook et. al. [8] and the Carrier Corporation [9], for example, have provided two of the more complete proposals. Standards Project Committee 137P of the American Society of Heating, Refrigerating, and Air-Conditioning Engineers, Inc. (ASHRAE) is presently working to develop a test method [10]. Engineering subcommittee 290P of the Air-Conditioning and Refrigeration Institute (ARI) is developing a product rating standard [11]. NIST and Carrier have given more emphasis to integrated HP/WH appliances having a water heating only mode than to heat pumps having a desuperheater. Cook et. al. and ASHRAE Standards Project Committee 137P, on the other hand, have given more emphasis to desuperheaters. ARI subcommittee $290 \mathrm{P}$ is attempting to address both general categories of appliances, and in addition to air-source units, cover water-source and ground-source appliances.

Although not yet benefitting from having a unit to test in the laboratory, the development process has progressed using information gained from several sources. For example, limited field testing of a heat pump system having a desuperheater and laboratory tests on conventional water heaters provided insight into the water heating characteristics of integrated HP/WH appliances $[12,13]$. An hour-by-hour computer simulation of an integrated HP/WH appliance having a water heating only mode [14] was used to conduct parametric studies that showed the relative effects of different variables (e.g., daily hot water usage, hot water draw schedule). Information gained from a manufacturer of a variable-speed 
integrated $\mathrm{HP} / \mathrm{WH}$ appliance, including aggregate results from fieldmonitored prototype units, has also aided NIST.

Laboratory testing of a unit capable of operating in six modes, including a water heating only mode, will be conducted at NIST in the immediate future. Such testing will help evaluate the proposed methodology, validate calculational procedures, and provide information for making any needed additions and modifications.

\section{SCOPE AND PURPOSE}

The NIST work is focusing on residential systems. The integrated appliance is to include an air-to-air heat pump which is electrically driven using single-phase power and has a rated capacity of less than $65,000 \mathrm{Btu} / \mathrm{h}$. The appliance is also to include a single, storage-type water heater having a rated capacity of less than 120 gallons. The key operating features of the appliance type considered are detailed in section 3.2 .

The purpose of the proposed rating methodology is to provide an approach for estimating seasonal operating costs and coefficients of performance. These seasonal values, which may be combined to get annual quantities, provide a means for comparing different integrated heat pump/water heating appliances and for comparing an integrated HP/WH appliance against a separate heat pump and water heater. Seasonal and annual operating costs also provide a relative comparison between an integrated appliance and a separate furnace, air conditioner, and water heater. 


\section{APPLIANCE DESCRIPTION}

\subsection{Generic Description}

Integrated heat pump/water heating appliances provide space heating and air-conditioning while also heating all or part of the water used for domestic consumption. The appliance consists of a heat pump, a refrigerant-to-potable water heat exchanger, and a storage-type water heater. The major components of the appliance are illustrated in Fig. 1. The refrigerant-to-water heat exchanger, which physically couples the heat pump to the water heater, is located immediately downstream of the compressor. This heat exchanger operates at times to desuperheat the refrigerant and at other times to desuperheat and condense the refrigerant. Water within the storage-type water heater is heated by removing it from the tank and circulating it through the refrigerant-towater heat exchanger. The electric resistance element(s) or the fossilfuel burner of the water heater usually contributes to heating water but efforts are made to minimize the contribution. The water-side piping shown in Fig. 1 is one of several ways recommended by manufacturers.

Integrated HP/WH appliances operate in multiple modes. For example, such appliances may operate in one or all three of the following water heating modes: combined space cooling and water heating ${ }^{1}$, combined space heating and water heating, and water heating only. For the combined space cooling and water heating mode, all or part of the energy that would be rejected to the outdoor air is instead used to heat water. For the combined space heating and water heating mode, part of the available space

${ }^{1}$ The phrase "and water heating" is often omitted when referring to a combined mode. 
heating capacity is used to heat water. For this mode, the heat pump will either run longer or operate at a higher speed (variable speed unit) to meet both heating loads. For the water heating only mode, the unit operates as it would in a conventional space heating mode except that, the refrigerant-to-water heat exchanger, not the indoor coil, is the condenser. Finally, most integrated HP/WH appliances will turn off the water pump and operate in the conventional space heating and airconditioning modes. The appliance opts for these "conventional" modes when it senses the water heater is recovered or, for some units, when all of the available capacity is needed to meet the space load.

Integrated heat pump/water heating appliances may be separated into two general categories. One category includes integrated appliances that have a water heating only mode and, in addition, may operate in one or both combined modes. These appliances are often referred to as fullcondensing units. The second category includes appliances which do not have a water heating only mode and heat water only when in a combined mode. These units are often referred to as desuperheaters.

The water heating only mode is singled-out as the key distinguishing feature because appliances having this operating mode provide on-demand water heating. These appliances "decide" when to initiate and terminate water heating by monitoring a temperature sensor placed within the water heater or by sensing the status of a water heater thermostat. The feature of on-demand water heating is important to the development of the proposed rating methodology because the unit is known to be heating water when needed. From a standpoint of developing a proposed test method, potential problems related to a lack of coincidence between hot water draws 
occurring and integrated HP/WH appliance operating, as is the case with heat pumps having a desuperheater, are avoided.

A second and more apparent consequence of a water heating only mode is continued levels of heat pump water heating during more temperate periods. The water heating contribution of an appliance not having a water heating only mode, by comparison, will decrease as the operating time of the heat pump decreases (because of decreased building loads) and will be zero if the homeowner elects to turn off the HVAC system for part of the year.

Categorizing an appliance as either a desuperheater or a fullcondensing unit may be misleading in some cases. For example, a desuperheater can provide "full-condensing", or at least, partial condensing of the refrigerant when heating watex in a combined space cooling mode if the outdoor fan is turned off. In this report, the terms desuperheating and full condensing are hereafter reserved for designating whether the condenser fan (as opposed to the condenser water pump) is on or off while in a water heating mode. If the condenser fan is turned off, the mode is referred to as a full-condensing mode; if the condenser fan is turned on, the mode is referred to as a desuperheating mode.

\subsection{Appliances Covered by the Proposed Methodology}

The type of integrated heat pump/water heating appliance addressed specifically in the text has six operating modes: (1) space heating only, (2) space cooling only, (3) water heating only, (4) combined space heating and water heating, (5) combined space cooling and full-condensing water heating, and (6) combined space cooling and desuperheating water heating. 
The specific appliance type also gives priority to conditioning the space over heating water, but otherwise operates to maximize the water heating capacity of the unit. In terms of operating modes, the appliance switches from a water heating only mode to a combined mode whenever space heating or cooling is needed. Moreover, the appliance switches to space heating only if it is unable to satisfy the building load while operating in the combined space heating mode. When this condition exists, the entire water heating load is recovered using the water heater resistive elements or fossil-fuel burner.

Because the appliance will occasionally be unable to heat water and, more importantly, because the homeowner wants to avoid running out of hot water, the single or upper tank thermostat will typically be set to the desired delivery temperature, usually between 125 and $140^{\circ} \mathrm{F}$. If a $2-$ element electric water heater is used, the lower thermostat is either turned all the way down $\left(110^{\circ} \mathrm{F}\right)$, or in some of the southernmost parts of the United States, is disconnected during much of the cooling season [15]. The appliance type addressed in the text may also have two other features. The first feature is that the controls of the unit may actively regulate the on/off status of the auxiliary resistive elements or fossilfuel burner. The second feature is that the integrated appliance may use the domestic hot water, rather than the conditioned space, as the heat source during a defrost cycle, i.e., water-source defrost.

\section{PROPOSED METHODOLOGY: AN OVERVIEW}

The energy consumption rate associated with meeting the seasonal building and water heating loads using an integrated HP/WH appliance is 
estimated using a bin calculation procedure. A bin approach provides a means for weighting the relative importance of each $5^{\circ} \mathrm{F}$ outdoor temperature bin based on the frequency that the outdoor temperature falls within each bin. As with rating conventional heat pumps, bins also account for how capacity and power usage of an integrated appliance vary as a function of the outdoor temperature. Unlike the rating of conventional heat pumps, however, up to three modes of operation (space only, combined, and water only) have to be considered in each bin. Capacity and power usage data is therefore needed not only for the space conditioning only modes but for the water heating modes as well.

The laboratory tests to determine capacities and power usages for the water heating modes are conducted with the water heater disconnected from the refrigerant-to-water heat exchanger. For such tests, water at a representative flow rate and temperature is supplied to the inlet of the refrigerant-to-water heat exchanger. Power usage, water-side capacity, and if applicable, air-side capacity depend to varying degrees on the water flow rate and the inlet temperature $[8,12,16,17]$. The representative values for flow rate and inlet temperature are determined from a simulated-use test, hereafter referred to as a recovery test.

A recovery test is a draw test. Besides providing a representative flow rate and inlet temperature, the test also acts as a basis for determining, within the bin calculation procedure, how much of the water heating load is met by the integrated appliance and how much is met by the water heater resistive element(s) or fossil-fuel burner. A laboratory basis for estimating the relative water heating contributions is needed because an integrated appliance having a water heating only mode can 
theoretically meet 100 per cent of the water heating load when operating above the heating season balance point. The results of field monitoring and laboratory draw tests show that, although the water heating contribution may be high, it typically does not approach 100 per cent $[18,19]$

For a recovery test, hot water draws are imposed, and the system is monitored as the tank is recovered. The appliance is allowed to operate in a normal manner with respect to "deciding" when to initiate and terminate water heating and controlling the on/off status of the auxiliary heater. The decision making feature of unit (i.e., its on-demand water heating capability) eliminates one important test variable: deciding when to cycle on and off the water pump during the lab tests. Because the test burden must be minimized, the tests which are run are as representative as possible. The NIST recommended recovery tests are described in section 5. 2 .

Within the bin calculation procedure, the water heating load, in units of $\mathrm{Btu} / \mathrm{h}$, is assumed to be independent of outdoor temperature. As a result, the water heating load is the same for each bin. This load is divided between the integrated appliance and the auxiliary heater before making any calculations as to the operating times in each mode. The water heating load is divided based on the results of the recovery tests.

Once the water heating load has been divided, logic within the calculation procedure is required for determining the fractional time spent in each water heating mode, combined versus water heating only, and the fractional time spent in each space conditioning mode, combined versus space only. The energy consumption rates of the appliance are readily 
determined once the operating times for each mode, in each bin, are calculated. Specifics on the calculation procedure and the laboratory testing are presented in the next two sections.

\section{LABORATORY TESTING}

The proposed laboratory testing includes recovery tests and capacity and power usage tests. A recovery test is a shortened version of the 24hour simulated-use test used for rating conventional storage-type water heaters. Capacity and power usage tests include the tests conducted when rating a conventional heat pump plus additional tests for determining the steady-state performance of the integrated appliance while operating in its water heating modes.

\subsection{Recovery Test: General Description}

For a recovery test, the integrated HP/WH appliance is tested with the storage-type water heater and the refrigerant-to-water heat exchanger connected. Hot water is withdrawn according to a specified schedule. The controls of the system are allowed to operate as they would under field conditions with regard to cycling the water pump and regulating the on/off status of the auxiliary element(s) or burner. The system is monitored to determine the water heating contributed by the integrated appliance versus the auxiliary heater. The flow rate and temperature of the water entering the refrigerant-to-water heat exchanger are measured during the recovery periods and later averaged. The averaged values are subsequently used when conducting the capacity and power usage tests. 
Two recovery tests are proposed. One test is conducted with the integrated appliance operating at a high water heating capacity and a second test is run at conditions that the unit has a low water heating capacity. The results are used to approximate how the water heating contribution of the integrated appliance (versus the auxiliary heater) varies as a function of the water heating capacity of the integrated appliance. A depiction of how the results would be correlated is shown in Fig. 2. For this hypothetical example, the auxiliary heater contributes 35 and 15 per cent of the water heating when the water heating capacities of the integrated appliance are 10.0 and $21.5 \mathrm{kBtu} / \mathrm{h}$, respectively. The relationship between the per cent water heating contribution and heat pump water heating capacity will be approximated as linear until performance data become available.

In each bin of the proposed calculation procedure, the total water heating load is divided between the integrated appliance and the auxiliary heater before determining the operating times in each mode. The water heating load allocated to the integrated appliance is based upon the water heating capacity of the unit and the results of the recovery test, Fig. 2. Water heating capacity varies depending upon the bin temperature and the water heating mode, combined or water heating only.

Besides yielding needed data for the bin calculation procedure, the recovery tests also implicitly provide a very important measure for ranking different integrated $\mathrm{HP} / \mathrm{WH}$ appliances. For example, the tests will credit an appliance that does a good job of keeping the auxiliary heater(s) off, either by actively controlling it or by removing and reintroducing water to the tank in a way that lessens the tendency of the 
auxiliary thermostat being tripped. The test may also differentiate between a unit that promptly begins heating water when a demand occurs and one that waits too long, thus requiring a greater contribution by the auxiliary heater. A safeguard to help prevent efforts to overly limit the contribution of the auxiliary heater(s) is proposed: a minimum water heater delivery temperature that must be exceeded during the duration of each hot water draw. The option of requiring a first-hour recovery test, as is used for rating conventional storage-type water heaters, to identify appliances that have a poor water heater recovery time was considered but eventually dismissed because of the already substantial testing burden associated with the proposed laboratory tests.

\subsection{Recovery Test: Proposed Testing Conditions}

In the laboratory, the first test is a recovery test. This first test is run with the unit operating in a water heating only mode at an outdoor temperature of $82^{\circ} \mathrm{F}$-- conditions where the unit has a high water heating capacity. During the first recovery test, the temperature and flow rate of the water entering the refrigerant-to-water heat exchanger are measured and later averaged. These average values are subsequently used when conducting capacity and power usage tests for operating modes that water heating occurs. The low water heating capacity test, the second recovery test, is conducted with the unit operating in a combined space heating and water heating mode at an outdoor temperature of $17^{\circ} \mathrm{F}$. When testing a variable-speed integrated appliance, the indoor fan is' operated at maximum speed so that the lowest possible water heating capacity results. The second recovery test is performed when the capacity 
and power usage tests for $17^{\circ} \mathrm{F}$ are conducted rather than immediately following the first recovery test at $82^{\circ} \mathrm{F}$.

The results of a recovery test will be influenced, to varying degrees, by the decision as to what are "representative" test conditions. Variables specified as part of a recovery test include the extent to which the water heater is recovered at the start of the test, the water main temperature, the hot water draw schedule, the tank auxiliary heater thermostat setting(s), and if sold without a tank, the type and the size of the water heater. The specified test conditions should be representative of those conditions found in the field and in accordance, as much as is possible, with the DoE rating procedure for water heaters [6].

For integrated appliances that are sold with a water heater, the upper or single auxiliary thermostat is set such that the mean temperature of the water above the heating element after cut-out is within the range of $135 \pm 5^{\circ} \mathrm{F}$. If applicable, the lower resistive thermostat is set such that the water above the lower heating element after cut-off is within the range of $110 \pm 5^{\circ} \mathrm{F}$. Six equally-spaced temperature sensors are installed in the water heater and used to determine if a proper thermostat setting is achieved. For an electric water heater, the wattage rating of any resistive element should not be less than $2.0 \mathrm{~kW}$, and the maximum power input requirement of the water heater should not exceed $12 \mathrm{~kW}$. For a gasfired water heater, the energy input of the unit should not exceed 75,000 $\mathrm{Btu} / \mathrm{h}$. For an oil-fired water heater, the energy input of the unit should not exceed $105,000 \mathrm{Btu} / \mathrm{h}$, and in addition, the nominal storage capacity of tank should not exceed 50 gallons. A 120 gallon storage capacity is the 
limit for electric and gas-fired water heaters. Most of the above specifications are taken from the DoE water heater test procedure [6].

For integrated HP/WH appliances that are sold without a water heater, the recovery tests are conducted using the same type of tank that is specified for testing add-on heat pump water heaters [6]. The water heater is an electric storage-type water heater having a measured volume of $47.0 \pm 1.0$ gallons and two $4.5 \mathrm{~kW}$ heating elements that are controlled such that both do not operate simultaneously. Notably, a water heater with a rated volume of 50 to 52 gallons will usually have a measured volume within the prescribed limits [20]. The energy factor of the water heater, as determined per DoE test procedures, is required to be $0.87 \pm$ 0.01. Because of the variability of thermostat temperature deadbands (i.e., the temperature drop before the resistive element(s) or fossil-fuel burner is enabled), the auxiliary heater(s) is manually controlled. During a recovery test, the decision to enable and disable a resistive element or burner is based on the temperature of a tank thermocouple positioned at the same height as the auxiliary heater thermostat. The setpoint temperature for the upper or single thermostat is $135^{\circ} \mathrm{F}$ and, if applicable, the setpoint for the lower themostat is $110^{\circ} \mathrm{F}$.

Representative deadbands for thermostats are still being investigated. For now, the deadbands proposed by the Carrier Corporation [9] are recommended: $22^{\circ} \mathrm{F}$ for the upper thermostat and $10^{\circ} \mathrm{F}$ for the lower thermostat. These temperatures are the nominal deadbands for the thermostats found on many electric water heaters [21].

The proposed draw schedule for the recovery test is two 16.1 gallon draws occurring one hour apart. This draw schedule is proposed in lieu of 
using six 10.71 gallon draws, as per the 24 -hour simulated-use test for water heaters [6]. The proposed draw profile provides a test of shorter duration while having draw volumes which are more representative of the draws seen in a home. Table 1, taken from the ASHRAE HVAC Systems and Applications Handbook [22], shows typical hot water volumes as a function of the end use. The draw volumes for a shower or bath range from 15 to 20 gallons. The hot water requirement for automatic dishwashing also falls within this same range. The hot water requirement for clothes washing corresponds to the highest usage while an assortment of end uses require 2 to 5 gallons. The proposed draw profile is viewed as a compromise between times when hot water is required for multiple end uses over a short time (e.g., 2 showers back-to-back, food preparation and simultaneous clothes washing, etc.) and the cases where an occasional hand washing occurs (which, by itself, may not cause a recovery). Notably, a 16.1 gallon draw, and not some other quantity between 15 and 20 gallons, is chosen because it is a multiple of 64.3 gallons, the draw volume used when testing conventional water heaters [6]. Within the context of a daily draw schedule, the third and fourth 16.1 gallon draws are assumed to occur after the tank is recovered from the first two draws.

An alternative draw schedule may be recommended once laboratory and field performance data for integrated heat pump/water heating appliances, especially ones having a water heating only mode, become available. The obvious goal is to specify a recovery test draw schedule that gives a representative indication of the water heating contributed by the integrated appliance versus the auxiliary heater in the field. 
The proposed recovery test begins with the water heater fully

recovered. During a draw, hot water is removed at a rate of 3 gallons per minute and make-up water at $58 \pm 2^{\circ} \mathrm{F}$ is supplied to the tank [6]. If the temperature of the water removed from the tank during the two 16.1 gallon draws falls below $110^{\circ} \mathrm{F}$, the test is considered invalid. A draw is terminated once the specified number of gallons is removed. As a possible option, the draw is terminated after a specified amount of energy is removed. The option of using energy as a basis for discontinuing a draw would be required if the temperature of the water removed from the tank varied considerably from the 130 to $140^{\circ} \mathrm{F}$ range. The recovery test is completed after both the integrated $\mathrm{HP} / \mathrm{WH}$ appliance and the resistive element(s) or fossil-fuel burner have discontinued heating water. The ratio of the water heating contributed by the auxiliary heater to the sum of the contributions by the integrated appliance and the auxiliary heater is then calculated. The ratios from the two recovery tests are plotted as shown in Fig. 2.

At the option of the manufacturer, the recovery test may be continued until the tank standby losses alone cause either the integrated appliance or the auxiliary heater to come on and recover the tank. If the integrated appliance recovers the tank before the auxiliary heater, the hourly water heating load associated with tank standby losses is included as part of the load met by the integrated appliance in the bin calculations. If the length of the recovery test is not extended, the standby losses are assumed to be distributed between the integrated appliance and the auxiliary heater in the same ratio as the water heating load associated with the draws. 


\subsection{Capacity and Power Usage Tests}

\subsubsection{Proposed Test Conditions}

The tests specified for rating a conventional heat pump are conducted when rating an integrated heat pump/water heating appliance [1-5]. The tests provide steady-state capacity and power usage data for the space conditioning only modes, i.e., air conditioning and space heating. The tests also yield cyclic and defrost performance data. The results from the cyclic and defrost tests, or the defaults used in lieu of testing, are applied to the water heating modes in addition to the space conditioning only modes. As an example, the defrost penalty associated with space heating only is used to adjust data for the combined space heating mode and the water heating only mode.

Capacity and power usage tests are performed to provide steady-state performance data for the combined and water heating only modes as well. For these tests, the storage-type water heater is decoupled from the system, and instead, constant temperature water is supplied at a constant flow rate to the refrigerant-to-water heat exchanger of the integrated appliance. The temperature and flow rate are set as determined from the first recovery test. Water heating capacity is determined from monitoring the flow rate and measuring the water-side temperature difference for the refxigerant-to-water heat exchanger. For the combined modes, the air-side capacity is measured the same way as for the space conditioning only modes [23].

A summary of proposed tests, including the recovery tests, is given in Tables 2 and 3 for a variable-speed, integrated HP/WH appliance. For the space cooling season (see Table 2), two steady-state capacity and 
power usage tests are proposed for each water heating mode: (1) combined space cooling and full condensing water heating, (2) combined space cooling and desuperheating water heating, and (3) water heating only. For a variable-speed appliance, 7 water heating mode tests (including 1 recovery test) are proposed for the space cooling (and water heating) season. The total number of space cooling season tests thus increases to 14, although the two cyclic tests are optional. For the space heating (and water heating) season, the proposed 6 water heating mode tests (again including 1 recovery test) increase the number of tests to 14 , three being optional (see Table 3). The additional tests are purposefully chosen at the same environmental chamber conditions and, where possible, compressor speed as designated for the space conditioning only mode tests. By so choosing, the increase in the number of tests is intended to result in the minimum possible increase in testing time.

The tests in Tables 2 and 3 , as well as the logic of the bin analysis, are specified assuming certain operating characteristics of variable-speed integrated HP/WH appliances. For the water heating only mode, the controls of the appliance are assumed to select a unique compressor speed for a particular outdoor temperature. Such a control strategy results if the key design objectives are to maximize the water heating recovery rate of the integrated appliance but while assuring the compressor is not overloaded. If other logic applies (e.g., a compressor speed which varies depending upon the time of the day, and possibly, the day of the week), another testing approach may have to be considered. The four water heating only mode tests are chosen because they span the temperature range in which such a mode contributes -- at least within a 
bin analysis of a variable-speed unit, i.e., typically from 42 to $82^{\circ} \mathrm{F}$. The number of water heating only tests could possibly be reduced from four to two if the unit operated at the same speed (e.g., maximum speed) for the 42 to $82^{\circ} \mathrm{F}$ outdoor temperature range.

For units having two space cooling combined modes, the laboratory tests are specified assuming that the appliance will operate predominantly in a full-condensing mode at lower outdoor temperatures and predominantly in a desuperheating mode at higher outdoor temperatures. Within the bin analysis, the unit is modelled as operating in a full-condensing combined mode for as long as possible, while still meeting the space cooling load, before switching to a desuperheating combined mode. For the heating season, the combined mode laboratory tests are structured assuming the unit operates at maximum compressor speed while varying the indoor fan speed to best match the space load. The laboratory tests and the logic of the bin analyses will have to be re-evaluated if the controls of future variable-speed integrated heat pump/water heating appliances deviate considerably from the perceived operating schemes.

With regard to single-speed integrated $\mathrm{HP} / \mathrm{WH}$ appliances, the projected tests are listed in Tables 4 and 5 . The recovery tests are again included. For units having two space cooling combined modes, a space heating combined mode, and a water heating only mode, a total of 10 additional tests are proposed. Reducing the number of combined mode tests may be possible if the slopes of the capacity and power usage curves for the combined modes can be approximated using the slopes of the curves for the space conditioning only modes (as is recommended for variable-speed units in section $5: 4$ ). 


\subsubsection{Frost Accumulation Test: Water-source}

For appliances that use the energy stored in the water heater during a defrost cycle, the manufacturer may chose to have the frost accumulation test(s) conducted with the water heater connected. The proposed changes to the existing air-source frost accumulation test include filling the tank with water and using the auxiliary resistive element(s) or fossilfuel burner to recover the tank. The thermostat setpoints are the same as for the recovery tests, $135^{\circ} \mathrm{F}$ for the single or upper thermostat and, if applicable, $110^{\circ} \mathrm{F}$ for the lower thermostat. The preliminary and actual test periods are conducted as per existing test procedures [1-5], except that the refrigerant-to-water heat exchanger is the evaporator during both defrost cycles. (The preliminary test period begins after at least onehalf hour of steady-state operation and ends with the completion of the first defrost cycle; the actual test period begins following this first defrost cycle and ends with the completion of the second defrost cycle.) The auxiliary resistive element(s) or fossil-fuel burner is disabled once the preliminary test period begins. By disabling, the possibility of the defrost for the actual test period (i.e., the second defrost) occurring with a fully recovered tank for one appliance and not another is avoided. During the second defrost cycle, the energy removed from the tank is recorded by making water-side measurements of the flow rate and the temperature change for the refrigerant-to-water heat exchanger.

The data collected during an air-source, frost accumulation test is recorded during a water-source, frost accumulation test except that the energy quantities are recorded for two sub-intervals of the test in addition to the aggregate results for the entire test. The two sub- 
intervals include (1) an initial period when frosting effects are negligible and (2) the entire frosting interval of the test, i.e., excluding the defrost cycle. The energy supplied in heating the space, the electrical energy used by the appliance, and the elapsed times corresponding to each energy quantity/sub-interval are recorded. The electrical energy usage for the entire test includes the energy used by the water pump during the defrost cycle. During the initial "no-frost" period, the air-side flow rate is measured more frequently than the 10minute intervals used when testing heat pumps [1-5]. Until laboratory data becomes available, measurement intervals of 3 minutes and an no-frost period lasting 15 minutes are recommended.

As with conventional heat pumps, the frost accumulation test(s) is conducted with the unit operating in a space heating only mode and outdoor environmental chamber conditions of $35^{\circ} \mathrm{F}$ dry bulb and $30^{\circ} \mathrm{F}$ dew-point (see Tables 3 and 5). For variable-speed units, the required test is conducted with the compressor operating at an intermediate speed [3]; an optional test may be conducted at maximum compressor speed. An approach for reducing the data from the frost accumulation test(s) is given in section 5.4.2. In this same section, a method is proposed for "extrapolating" the results from a frost accumulation test to correct steady-state data for the combined space heating mode, the water heating only mode, and if the optional test for variable-speed units at maximum compressor speed is not run, the space heating only mode as well. 


\subsection{Deriving Bin Performance Data}

\subsubsection{Steady-state Data: Emphasis on Variable-speed Units}

Within the bin analysis of a variable-speed integrated appliance, capacity and power usage values for the space conditioning only modes are determined using the same method specified for variable-speed heat pumps [3]. This procedure is briefly reviewed before discussing how the procedure is adapted for use with the combined modes. An adapted approach is required because less laboratory data is available for the combined modes than for the space conditioning only modes.

For the space conditioning only modes, the three regions of operation for the variable-speed unit are first determined. The three regions are determined by equating the capacity curves corresponding to maximum $(k=2)$ and minimum $(k=1)$ compressor speeds with the building load line. As depicted in Fig. 3a for the space cooling only mode, the unit is modelled as cycling for temperatures ranging from $65^{\circ} \mathrm{F}$ to $\mathrm{T}_{1}$, as operating over an intermediate-speed range while exactly meeting the building load from temperatures $T_{1}$ to $T_{2}$, and as operating at maximum speed for temperatures greater than $T_{2}$. For the specified intermediate speed (= min speed $+[\max$ speed - min speed]/3) that the unit is tested in the laboratory, a capacity curve and a power usage curve are generated using the results from the single intermediate-speed test and slopes which are calculated by weighted averaging of the slopes for the maximum and minimum speed curves [24]. The outdoor temperature $T_{0}$, where heat pump capacity matches the building load, is determined once the intermediate-speed curve is defined (Fig 3a). Referring to Fig. 3b, the corresponding values of power usage are determined from the intersection of $T_{1}, T_{2}$, and $T_{0}$, and the minimum 
speed, maximum speed, and intermediate-speed power usage curves, respectively. As described by Domanski [25], other values of power usage within the intermediate-speed range are derived after first performing a parabolic fit of the three corresponding energy efficiency ratios, Fig. 4. For bin temperatures between $T_{1}$ and $T_{2}$ then, power usage is determined by dividing heat pump capacity (which equals the building load within the intermediate-speed range) by EER. Referring to Fig. 3, capacity and power usage for temperatures less than $T_{1}$ are determined using the respective linear fits developed for minimum compressor speed $(k=1)$. For temperatures greater than $T_{2}$, capacity and power usage are determined from the linear fits for maximum compressor speed $(k=2)$.

For the combined modes, in general, the above approach is followed for determining space conditioning capacity and power usage as a function of the outdoor temperature. For the combined space cooling and water heating mode(s), the above method is modified to compensate for not having data from an intermediate-speed test and for having results from one rather than two tests for each of the minimum and maximum compressor speeds. Slopes are assigned -- much like is done in deriving equations for the space cooling only mode at the intermediate compressor speed -for the minimum and maximum compressor speeds in order to generate capacity and power usage curves. Figure 5 depicts the case of a unit having two space cooling combined modes. (The darkened points are derived values.) As proposed, the combined space cooling capacity and power usage slopes are assumed to be the same as for the space cooling only mode. Once laboratory data becomes available, a small correction factor may be added. 
In the same way as for the space cooling only mode, the temperature ranges corresponding to cyclic, intermediate-speed, and maximum-speed operation while in a combined mode are determined. Temperature $T_{1}$ separates the cyclic range from the intermediated-speed range; temperature $\mathrm{T}_{2}$ separates the intermediate-speed range from the maximum-speed range. A single prime is used to designate a full-condensing combined mode while a double prime is used to depict a desuperheating combined mode. As before, power usage values for temperatures $T_{1}$ and $T_{2}$ are determined. In lieu of not having data from an intermediate-speed test for the combined space cooling mode, a linear fit of combined mode EER versus outdoor temperature is proposed until laboratory testing provides insight as to a better approach, possibly one which is tied to the parabolic fit of EER for the space cooling only mode, Fig. 4. Power usages for temperatures between $T_{1}$ and $\mathrm{T}_{2}$ are determined by dividing the building load by the combined mode EER. For the chosen example, the unit is assumed to operate in a fullcondensing mode until it is no longer able to meet the space load. In graphical terms, the unit operates in a full-condensing combined mode for temperatures less than $T_{2}^{\prime}$ and in a desuperheating combined mode for temperatures greater than $\mathrm{T}_{2}^{\prime}$.

For the combined space cooling mode(s), the water heating capacity curves for minimum and maximum compressor speed are developed using the same approach as described for the space cooling capacity curves: by assigning a slope and using the single data point to get capacity as a function of the outdoor temperature. A depiction of the resulting curves is shown in Fig. 6. For all combined modes, water heating capacity is determined using linear interpolation within the intermediate-speed range. 
Because two tests are proposed for the space heating combined mode at minimum compressor speed, assigning two capacity slopes and a power usage slope is avoided. For the maximum compressor speed, however, slopes (space capacity, water heating capacity, and power usage) are assigned. Until laboratory results become available, the slopes for maximum compressor speed are approximated by multiplying the respective slopes for the minimum compressor speed by the ratio of the maximum-to-minimum speed slopes for the space heating only mode. The lack of intermediate-speed data and the effect on determining power within the intermediate-speed range is handled in the same manner as described for the combined space cooling mode(s).

For the water heating only mode, linear interpolation of both capacity and power are used as shown in Fig. 7. As mentioned earlier, the proposed methodology covers variable-speed units that operate at a unique operating speed for a given outdoor temperature.

For single-speed integrated heat pump/water heating appliances, the above steps for variable-speed units are avoided if two tests are conducted for each combined mode. Capacity and power usages, for all modes, are determined using linear interpolation.

\subsubsection{Frosting and Defrosting Effects}

For both variable and single-speed units, corrections are made to account for the aggregate performance degradation caused by frosting of the outdoor coil and the need to occasionally defrost this coil. NIST has given emphasis to developing a proposed algorithm for units having watersource defrost. The algorithm includes two steps: reducing the laboratory data from the frost accumulation test(s) and then using the 
results to correct data for the water heating only and combined space heating modes.

The proposed algorithm for reducing the results from a water-source, frost accumulation test is outlined below. The algorithm is formulated based on the rationale that the water heater must be recovered (i.e., the energy removed must be replaced) following a water-source defrost cycle. Such a recovery is presently not part of the proposed frost accumulation test, although making it optional will receive consideration.

For calculation purposes, the tank is assumed to be recovered by the integrated appliance alone, i.e., no auxiliary heat. (If field and laboratory data suggest otherwise, appropriate modifications will be made.) A defrost resulting from operating in a space heating only mode is assumed to be recovered with the unit operating in a combined space heating mode. As a result, the performance data for the space heating only mode has factored into it a combined mode contribution for those temperatures that frosting/defrosting degrade performance.

The time required to replace the energy removed from the water heater during the defrost cycle is determined first. This time is calculated given the measured energy removed, $Q_{w, d f}$, and the water heating capacity of the integrated appliance while operating in a combined space heating mode. The combined mode water heating capacity, as well as the corresponding space heating capacity and power usage, at $35^{\circ} \mathrm{F}$ are derived from the steady-state equations (curves) that were described in section 5.4.1. Space heating capacity and power usage are used in the data reduction process and so are determined at the same time. For a singlespeed unit where two capacity and power usage tests are conducted, for example, the steady-state data is determined using the following. 


$$
\begin{aligned}
& \dot{Q}_{c, s}(35)^{*}=\dot{Q}_{c, s}(17)+\frac{\dot{Q}_{c, s}(47)-\dot{Q}_{c, s}(17)}{47-17}(35-17) . \\
& \dot{Q}_{c, w}(35)^{*}=\dot{Q}_{c, w}(17)+\frac{\dot{Q}_{c, w}(47)-\dot{Q}_{c, w}(17)}{47-17}(35-17) \\
& \dot{E}_{c}(35)^{*}=\dot{E}_{c}(17)+\frac{\dot{E}_{c}(47)-\dot{E}_{c}(17)}{47-17}
\end{aligned}
$$

The asterisks in the above equations designate that the steady-state values have not been corrected for frosting/defrosting effects. For variable-speed systems, the combined mode equations corresponding to maximum indoor fan speed and maximum compressor speed are recommended for calculating the quantities in equations 1 through 3 even though the recovery could occur at another fan speed.

Given the combined mode water heating capacity, the time required to recover the tank is calculated.

$$
t_{r t}=\frac{Q_{w, d f}}{\dot{Q}_{c, w}(35)^{*}}
$$

Using the uncorrected combined mode water heating capacity in equation 4 is recommended because the recovery period is expected to be short enough that no appreciable degradation in capacity will occur.

From the remaining results of the water-source, frost accumulation test -- the net space heating delivered, $Q_{d e f}(35)$, the total electrical energy used by the integrated appliance, $E_{d e f}(35)$, and the elapsed times that the frosting and defrosting intervals lasted, $t_{f_{x}}$ and $t_{d f}$ respectively -- the average space heating capacity and the average power usage for the space heating only mode at $35^{\circ} \mathrm{F}$ are calculated.

$$
\dot{Q}_{s o}(35)=\frac{Q_{d e f}(35)+\dot{Q}_{c, s}(35)^{*} \cdot t_{r t}}{t_{f r}+t_{d r}+t_{r t}}
$$


$\dot{E}_{s o}(35)=\frac{E_{\text {def }}(35)+\dot{E}_{c}(35)^{*} \cdot t_{r t}}{t_{f r}+t_{d r}+t_{r t}}$

Equations 5 and 6 are used to reduce the data from the required and, if applicable, optional frost accumulation tests. If the optional test for variable-speed units is not conducted, a method is needed for correcting the performance data at maximum compressor speed using the results from the intermediate-speed, frost accumulation test. Likewise, an approach is required for "extrapolating" the results from a frost accumulation test in order to correct performance data for the combined space heating and water heating only modes. The proposed approach for correcting the pertinent performance data is presented below.

The assumptions behind the proposed approach for using the results from the frost accumulation test to correct steady-state data for the water heating modes and, if applicable, the space heating only mode at maximum compressor speed are as listed.

(1) The ratio of the average capacity (power usage) during the frosting period to the average capacity (power usage) during the no-frost period, as determined from the frost accumulation test, is the same for each operating mode. For example, if the ratio for space heating capacity is determined to be 0.97 , then a 3 per cent loss of capacity, on average, is assumed to occur for the each of the combined mode capacities as a result of frost accumulation. With this approach, the capacity and power usage from the no-frost period are assumed to approximate steady-state data that has not been corrected for frosting/defrosting effects.

(2) For the prescribed test conditions, a defrost cycle is initiated every time a specific amount of energy is gained by the refrigerant from the outdoor air. In this report, the critical energy quantity is designated as $Q_{e v, p_{r}}$. This quantity is either measured in the laboratory or calculated using laboratory data of the space heating energy and electrical energy used during the frosting period.

(3) During the defrost cycle, the same amount of energy is removed from the water heater. The energy quantity, $Q_{n, d f}$, is measure during the frost accumulation test. 
(4) During the water-source defrost cycle, the same amount of electrical energy is used by the integrated appliance. The energy used, $E_{d \rho}$, is determined from the difference of the electrical energy used during the entire test and the energy used during the frosting period.

(5) The water-source defrost cycle always takes the same amount of time when the outdoor conditions are $35^{\circ} \mathrm{F}$ dry bulb temperature and $30^{\circ} \mathrm{F}$ dew-point temperature and the water heater is recovered to the extent that it was in the frost accumulation test. Specifically, the defrost time $t_{d f}$ is constant and equal to the time recorded during the laboratory test.

(6) A defrost cycle initiated because the unit was operating in a combined space heating mode is followed by a recovery of the water heater with the unit operating in a combined mode.

(7) A defrost cycle initiated because the unit was operating in a water heating only mode is followed by a recovery of the water heater with the unit operating in a water heating only mode.

Assumptions 1 and 2 are the key points needing validation via experimental studies. Assumptions 3 through 5 are directly linked with assumption 2 .

As alluded to above, three distinct periods are considered when correcting the steady-state data: the frosting period, the defrost cycle, and the recovery period. Capacities and power usages are first corrected for the effect of frosting. Capacities are then corrected for the time lost when no useful heating occurs because of a defrost cycle. Power usages for each operating mode, on the other hand, are all modified to incorporate the energy used during a defrost cycle. The water heating required to offset the energy removed from the tank during the defrost cycle is accounted for by determining the additional time required for the recovery. The resulting average capacities are the net outputs (space heating or water heating) for the frosting and water heater recovery periods, divided by the total elapsed time for frosting, defrosting, and tank recovery. The resulting average power usages are the sum of the electric energy used during frosting, defrosting and water heater recovery periods divided by the total elapsed time for the same three periods. 
The relative effect of frosting on capacity and power usage is determined by dividing the average values for the frosting period (equations 7 and 8 ) by the average values for the initial "no-frost" period (equations 9 and 10) of the frost accumulation test. The resulting capacity and power usage ratios (equations 11 and 12) are then used for correcting all pertinent steady-state data.

$$
\begin{array}{ll}
\dot{Q}_{s, f x}(35)=\frac{Q_{s, f r}}{t_{f r}} & \text { (Frosting period) } \\
\dot{E}_{f r}(35)=\frac{E_{f r}}{t_{f r}} & \text { (Frosting period) } \\
\dot{Q}_{s, n f}(35)=\frac{Q_{s, n f}}{t_{n f}} & \text { (No-frost period) } \\
\dot{E}_{n f}(35)=\frac{E_{n f}}{t_{n f}} & \text { (No-frost period) } \\
C R=\dot{Q}_{s, f r}(35) / \dot{Q}_{s, n f} \text { (35) } & \text { (Capacity Ratio) } \\
P R=\dot{E}_{f r} \text { (35) / } \dot{E}_{n f} \text { (35) } & \text { (Power Usage Ratio) }
\end{array}
$$

The equations for calculating corrected capacity and power usage values are presented below for each operating mode.

\section{Combined Space Heating and Water Heating}

$$
\begin{aligned}
& \dot{Q}_{c, w}(35)=\frac{\dot{Q}_{c, w}(35)^{*} \cdot C R \cdot t_{c, f r}}{t_{c, f r}+t_{d f}+t_{r t}} \\
& \dot{Q}_{c, s}(35)=\frac{\dot{Q}_{c, s}(35)^{*} \cdot C R \cdot t_{c, f r}+\dot{Q}_{c, s}(35)^{*} \cdot t_{r t}}{t_{c, f r}+{ }_{d f}+t_{r t}} \\
& \dot{E}_{c}(35)=\frac{\dot{E}_{c}(35)^{*} \cdot P R \cdot t_{c, f r}+E_{d f}+\dot{E}_{c}(35)^{*} \cdot t_{r t}}{t_{c, f r}+t_{d f}+t_{r t}}
\end{aligned}
$$


The length of the water heater recovery period, $\tau_{r t}$, is calculated using equation 4. As discussed with equation 4, the water heater recovery period is expected to be short enough that frosting effects will be negligible. Thus in equations 14 and 15 for the combined mode and in similar equations that follow for the other modes, the space heating capacity and power usage contributions for the water heater recovery period (the last product in each numerator) are not corrected for frosting effects using $C R$ and $P R$. If laboratory or field results show that frosting effects are appreciable, the capacity and power usage ratios will be used to adjust the data for the water heater recovery period.

For equations 13-15, the length of the frosting period if the unit was operating in a combined mode, $t_{c, l}$, , is estimated by

$$
t_{c, f r}=\frac{Q_{e v, f r}}{\dot{Q}_{c, w}(35)^{\star} \cdot C R+\dot{Q}_{c, s}(35)^{\star} \cdot C R-\left[\dot{E}_{c}(35)^{\star} \cdot P R \cdot 3.413\right]}
$$

where the energy removed from the outdoor air by the refrigerant during the frosting period, $Q_{v, p_{r}}$, is either measured during the frost accumulation test or calculated, as follows, by performing an energy balance on the refrigeration cycle.

$$
Q_{\text {ev,fr }}=Q_{s, f r}{ }^{-} E_{f r} \cdot 3.413
$$

Water Heating Only Mode

$$
\begin{aligned}
& \dot{q}_{w 0}(35)=\frac{\dot{Q}_{w 0}(35)^{*} \cdot C R \cdot t_{w o, f r}}{t_{w 0, f r}+t_{d f}+t_{r t}} \\
& \dot{E}_{w o}(35)=\frac{\dot{E}_{w 0}(35)^{\star} \cdot P R \cdot t_{w o, f r}+E_{d f}+\dot{E}_{w o}(35) * t_{r t}}{t_{w o, f r}+t_{d f}+t_{r t}}
\end{aligned}
$$


The length of the water heater recovery period, $t_{r t}$, is different for the - water heating only mode because the tank recovery is assumed to occur in the water heating only mode, not the combined mode as in all other cases.

$$
t_{r t}=\frac{Q_{w, d f}}{\dot{Q}_{w 0}(35)^{*}}
$$

The length of the frosting period if the unit was operating in a water heating only mode, $t_{w 0, f_{x}}$, is estimated by

$$
t_{w o, f r}=\frac{Q_{\text {ev,fr }}}{\dot{Q}_{w o}(35)^{\star} \cdot \mathrm{CR}-\dot{\mathrm{E}}_{\text {wo }}(35)^{\star} \cdot \mathrm{PR} \cdot 3.413}
$$

where the energy removed from the outdoor air by the refrigerant during the frosting period, $Q_{\ell^{\prime}, f_{x}}$, is the same as for the combined mode calculations.

Space Heating Only: Variable-Speed Units

$$
\begin{aligned}
& \dot{Q}_{s o}^{k=2}(35)=\frac{\dot{Q}_{s o}^{k=2}(35)^{*} \cdot C R \cdot t_{s o, f r}+\dot{Q}_{c, s}(35)^{*} \cdot t_{r t}}{t_{s o, f r}+t_{d f}+t_{r t}} \\
& \dot{E}_{s o}^{k=2}(35)=\frac{\dot{E}_{s o}^{k=2}(35)^{*} \cdot P R \cdot t_{s o, f r}+E_{d f}+\dot{E}_{c}(35)^{*} \cdot t_{r t}}{t_{s o, f r}+t_{d f}+t_{r t}}
\end{aligned}
$$

The length of the water heater recovery period, $t_{r t}$, is calculated using equation 4 because the recovery is assumed to occur with the unit operating in a combined mode at maximum compressor and fan speeds. The length of the frosting period if the unit was operating in a space heating only mode at maximum speed, $t_{30,1 x}$, is estimated by

$$
t_{\text {so, fr }}=\frac{Q_{\text {ev, fr }}}{\dot{Q}_{\text {so }}^{k=2}(35)^{*} \cdot C R-\dot{E}_{\text {so }}^{k=2}(35)^{*} \cdot P R \cdot 3.413}
$$

where $Q_{0 v, f I}$ is the same as for the other modes. The superscript $k=2$ is uṣed to clarify that equations 22,23 and 24 are only applicable to 
variable-speed appliances. The equations are used in lieu of conducting the optional frost accumulation test at maximum compressor speed.

Asterisks in the above sets of equations are again used to designate steady-state data that has not been corrected for frosting/defrosting and tank recovery effects. If conducted, the data from the optional frost accumulation test for variable-speed appliances (i.e., at maximum speed) is used within the equations to correct data for the combined and water heating only modes; otherwise, the data from the intermediate-speed test is used.

With regard to using the corrected capacity and power usage values, the procedure is the same as for conventional heat pumps, only now with two additional modes, combined and water heating only [1-5]. The corrected data points for $35^{\circ} \mathrm{F}$ outdoor temperature are used with the steady-state data for $17^{\circ} \mathrm{F}$ to depict performance for the temperature range that frosting/defrosting and tank recovery effects occur. To be consistent with heat pump test procedures [1-5], an outdoor temperature range of 17 to 45 is recommended. Future considerations, however, should be given to lowering the upper bound to $40^{\circ} \mathrm{F}$, as proposed by the Carrier Corporation [9].

\section{CALCULATION PROCEDURE}

An estimate of the seasonal performance of an integrated HP/WH appliance is determined using a modified version of the heat pump calculation procedure. As with rating a heat pump, bin calculations are conducted to estimate performance for the space cooling season and the space heating season. Water heating occurs in both seasons. As compared to the method used for heat pumps, however, the proposed calculation 
procedure is more complex because of the multiple operating modes and the addition of a water heating load. Because of these additional factors, the proposed methodology includes conditional steps.

The water heating load used in the calculation procedure is the sum of the loads associated with tank standby losses and the daily usage of hot water. The standby losses are determined by knowing the energy factor and the recovery efficiency of the storage-type water heater. The equation relating these variables is

$$
E_{Q}=\frac{Q_{D H W}}{E_{t}}=\frac{Q_{D H W}}{\frac{Q_{D H W}}{\eta_{R}}+\frac{Q_{t K}}{\eta_{R}}+E_{\text {QUX }}} .
$$

The energy factor, $E_{f}$, the recovery efficiency, $\eta_{R}$, and the daily electrical energy usage by the water heater if gas or oil-fired, $E_{a u x}$, are those quantities determined using the DoE water heater test procedure [6]. After rearranging, the standby losses, $Q_{t k}$, may be expressed as

$$
Q_{t K}=Q_{D E W}\left[\frac{\eta_{R}}{E_{q}}-1\right]-\eta_{R} \cdot E_{Q u x} \text {, }
$$

where the daily hot water load is computed using

$$
Q_{D E W}=\rho \cdot V_{D E W} \cdot C_{p}\left(T_{D E W}-T_{m}\right) .
$$

For the 24-hour simulated use test used to determine the energy factor of a water heater, the domestic water heating load is based upon a draw of 64.3 gallons, a water main temperature of $58^{\circ} \mathrm{F}$, and an outlet temperature of $135^{\circ} \mathrm{F}$. Using equation 27 , the water heating load, $Q_{D B W}$, is thus known $(40,850 \mathrm{Btu})$. For an electric water heater, $\mathrm{E}_{\mathrm{aux}}$ is zero and the recovery efficiency, $\eta_{R}$, is $0.98[6]$. As a result, the standby losses of an 
electric water heater are a direct function of the energy factor as shown in Table 6.

The bin calculation is organized so that the total seasonal water heating load is distributed proportionally among the bins according to the fractional bin hours. This distribution occurs by assigning the same water heating load, expressed as an hourly rate quantity, to each bin. For rating purposes, the water heating load used in the proposed calculation procedure is the same as the load used for rating conventional water heaters, 40,850 Btu/day or $1702 \mathrm{Btu} / \mathrm{h}$. Although the water heating load in a home is not evenly distributed throughout the day, such an approach is permissible since the water heating contributions of the integrated appliance and the auxiliary heater are based on the recovery test and not on the mechanics of the bin calculation procedure.

\subsection{Space Cooling Season}

A completed bin calculation worksheet for a variable-speed integrated appliance is shown in Table 7 (note: Table 7 continues on a second page). This table is referred to repeatedly while discussing the calculation procedure. Some of the columns in Table 7 are not required for determining the energy consumption rate of the integrated appliance and auxiliary heater in satisfying the loads. The extra columns are included, nevertheless, in hope of making the calculation process easier to follow. For example purposes, the water heater of the integrated appliance is assumed to be electric. The calculation procedure may be extended to cover systems with a gas or oil-fired water heater if the recovery efficiency, $\eta_{R}$, the auxiliary electrical energy usage, $E_{a u x}$, and the energy factor, $E_{f}$, are all known. 
The distribution of fractional bin hours (column C) is the same as that used for rating a conventional heat pump during the space cooling season $[1,4]$. The building load (column E) is assigned using

$$
B L\left(T_{j}\right)=\dot{Q}_{s s}^{k=2}(95) \frac{T_{j}-65}{1.1[95-65]} \quad(B t u / h)
$$

where 1.1 is the 10 per cent oversizing factor. The superscript $k=2$ denotes that the capacity at maximum compressor speed is used if rating a variable-speed unit. The relationship between the building load and the outdoor bin temperature is the same as that used for rating heat pumps [15]. The use of equation 28 is valid because oversizing the integrated appliance due to the additional water heating load is not expected.

The total water heating load (column F) is the sum of the hourly rates for the domestic water heating load and the tank standby losses. As stated above, the domestic water heating load used for rating purposes is 1702 Btu/h. For the example shown, the standby losses of the water heater are $193 \mathrm{Btu} / \mathrm{h}$ (which corresponds to an electric water heater having an energy factor of 0.88 as shown in Table 6). Thus, the total water heating load, for all sub-bins, is $1895 \mathrm{Btu} / \mathrm{h}$.

Steady-state capacity and power usage values are assigned for the three pertinent operating modes using the respective equations. These equations are generated using the laboratory data from the capacity and power usage tests, including the frost accumulation test(s). For a variable-speed unit, as reviewed earlier, the building load also affects the relationship between capacity and outdoor temperature, and power usage and outdoor temperature. For the space conditioning only modes, the equations relating capacity and power usage to the outdoor temperature are the same as for a conventional heat pump [1-5].. For the water heating only 
mode, capacity and power usage values for a given outdoor temperature are determined from linear interpolation of the laboratory data, as consistent with the example shown in Fig. 7. For the combined modes, the proposed methodology for generating the capacity and power usage equations is described in section 5.4 .

The capacity and power usage values in Tables 7 were generated from preliminary data provided by a manufacturer of an integrated heat pump/water heating appliance. Referring to Table 7, the combined mode space cooling capacity, water heating capacity, and power usage are listed in columns $\mathrm{J}, \mathrm{K}$, and $\mathrm{L}$. Columns 0 and $\mathrm{P}$ list the water heating capacity and power usage for the water heating only mode. Entries for the space cooling only mode are given in columns $S$ and $T$ on page 2 of Table 7 .

After the loads and steady-state capacity and power usage entries are made, fractional sub-bin hours (column D) are assigned to two separate subbins. One sub-bin designates times when the integrated appliance begins heating water in a combined mode. The second sub-bin designates times when the unit begins heating water in a water heating only mode. These sub-bins provide a logical mechanism for estimating how much water heating is contributed with the unit operating in a combined mode versus a water heating only mode. As discussed earlier, the results of the recovery test play the predominant role in determining the water heating contributed by the integrated appliance versus the auxiliary heater.

In Table 7 , the combined mode sub-bin always precedes the water heating only mode sub-bin (refer to column AG). The fractional bin hours (column C) are allocated between the two sub-bins based on the maximum space load factor (column G). The maximum space load factor is 


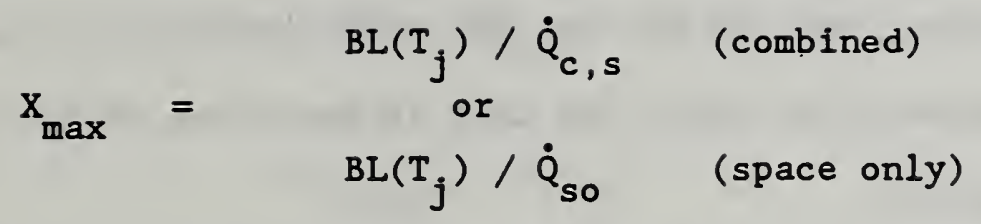

whichever is greater while being less than or equal to 1 . If $X_{m a x}$ is calculated as being greater than 1 , then $X_{\max }$ is set equal to 1 .

The maximum space load factor indicates the likelihood that water heating begins. while operating in a combined mode: the larger the ratio, the greater the chance of the unit having to meet the space and water loads simultaneously. Conversely, the unit is more likely to initiate water heating in a water heating only mode as the ratio decreases.

The fractional sub-bin hours for times when water heating begins in a combined mode are determined by multiplying the maximum space load factor (column $G$ ) by the fractional bin hours (column $C$ ). The fractional sub-bin hours for times when water heating begins in the water heating only mode equal the product of $\left(1-\mathrm{X}_{\max }\right)$ and the fractional bin hours (or the total fractional bin hours minus the sub-bin hours for the combined mode). Referring to the entries for the $67^{\circ} \mathrm{F}$ temperature bin, the maximum space load factor is $0.1677(2230 / 13300)$. The fractional sub-bin hours for times when water heating begins in a combined mode are $0.0359(0.1677 * 0.214)$. The remaining fractional bin hours, $0.1781(0.2140-0.0359)$, are allocated to the sub-bin designating times when water heating begins in a water heating only mode. For those bins where the maximum space load factor equals 1 , the sub-bin for the water heating only mode is omitted from the bin worksheet because the number of sub-bin hours is zero. As shown in Table 7 for temperature bins greater than or equal to $77^{\circ} \mathrm{F}$, the variablespeed integrated appliance only contributes to heating water while operating in a combined mode. For the higher temperatures, the variable- 
speed unit modulates to continually meet the space load. For a singlespeed unit, by comparison, the sub-bin for the water heating only mode is discontinued only in those bins where the unit is operating above the cooling load balance point.

Once the fractional sub-bin hours are allocated, the water heating contribution of the integrated HP/WH appliance is determined for each subbin. The contribution is based upon the results of the laboratory recovery tests. For the example shown in Table 7, the theoretical relationship given in Fig. 2 is assumed (the contribution of the integrated appliance equals 100 minus the ordinate). The entry in column $\mathrm{H}$ corresponds to the percentage of water heating contributed by the integrated HP/WH appliance. Using Fig. 2, the percentage is determined given the water heating capacity of the unit for the mode in which it begins heating water. As shown for the two $67^{\circ} \mathrm{F}$ sub-bins, a 68.5 per cent contribution is made when the water heating capacity is $12,000 \mathrm{Btu} / \mathrm{h}$ (combined mode) and an 85.0 per cent contribution occurs for a capacity of $21,500 \mathrm{Btu} / \mathrm{h}$ (water heating only mode). The water heating load allocated to the integrated appliance (column I) is the product of the total water heating load (column F) and the per cent contribution divided by 100 .

\subsubsection{Load Factor Calculations: Water Heating Begins in a Combined Mode}

The load factor for each operating mode is determined such that the building load and allocated water heating load are satisfied. For subbins where the unit begins heating water' in a combined mode, two load factors are calculated: one for the space load and one for the water heating load. The load factor for the combined mode (column M) is determined by finding which load is satisfied first, i.e., 


$$
\begin{aligned}
& B L\left(T_{j}\right) / \dot{Q}_{c, s} \\
& x_{c}=\quad \text { or } \text { WL }_{h p, \max } / \dot{Q}_{c, w}
\end{aligned}
$$

whichever is smaller. Two different calculation sequences follow depending upon which load is satisfied first.

If the water heating load is met first, the unit switches to a space cooling only mode until the remaining building load is satisfied. Since the entire water heating load was met while operating in a combined mode, the entry in column $\mathrm{N}$ is the same as column $\mathrm{I}$. The load factor (column Q) and the water heating contribution (column R) for the water heating only mode are both zero. The load factor for the space cooling only mode is determined from,

$$
x_{s o}=\left[B L\left(T_{j}\right)-\dot{Q}_{c, s} \cdot x_{c}\right] / \dot{Q}_{s o}
$$

The above calculation sequence is most often repeated in completing the bin worksheet. For those bins in which the maximum space load factor $\left(\mathrm{X}_{\max }\right.$ ) is 1, the only two possible sequences are the above described switching from a combined mode to a space cooling only mode and the case where the unit operates the entire hour in a combined mode. Because of the structure of the bin analysis, especially with regard to distributing the daily water heating load evenly to each hour, the latter possibility is very unlikely.

If the space load is met first, the unit switches to a water heating only mode until the remaining load is satisfied. The water heating load met while operating in a combined mode (column $N$ ) is determined using

$$
\mathrm{WL}_{\mathrm{hp}, \mathrm{c}}=\mathrm{X}_{\mathrm{c}} \cdot \dot{\mathrm{Q}}_{\mathrm{c}, \mathrm{w}} \text {. }
$$

The load factor for the water heating only mode is calculated by determining the fractional operating time required to meet the remaining 
water heating load. This load factor, when, added to the load factor for the combined mode, cannot be greater than one. Mathematically,

$$
x_{\text {wo }}=\frac{\left(W L_{h p, \max }-W L_{h p, c}\right) / \dot{Q}_{\text {wo }}}{1-x_{c}}
$$

whichever is smaller. The water heating contribution while operating in a water heating only mode (column $R$ ) equals the product of the water heating capacity and the load factor $\left(\dot{Q}_{w_{0}} \cdot X_{w_{0}}\right)$.

If part of the water heating load allocated to the integrated. appliance is not met for any calculation sequence, the remaining load is entered in column $X$. A water heating load would remain, for example, if the second option in equation 33 was used in the calculation sequence. This remaining water heating load is assumed to be met using auxiliary heat.

6.1.2 Load Factor Calculations: Water Heating Begins in a Water Heating Only Mode

For sub-bins in which the unit begins water heating in a water heating only mode, two load factors are calculated. One load factor is calculated for the case where the entire allocated water heating load is satisfied while operating in the water heating only mode. A second load factor is calculated to ensure that the unit switches modes timely enough to satisfy the space cooling load. Satisfying the space load is ensured if the sum of the load factor for the water heating only mode and the maximum space load factor, $X_{m a x}$, is less than or equal to 1 . In equation form, the load factor for the water heating only mode is 


$$
\mathrm{X}_{\text {wo }}=\quad \begin{gathered}
\text { Wh } I_{\text {hp }, \max } / \dot{\mathrm{Q}}_{\text {wo }} \\
\text { or } \\
1-\mathrm{X}_{\max }
\end{gathered}
$$

whichever is smaller. For the $67^{\circ} \mathrm{F}$ sub-bin for the water heating only mode (refer to column AG), the load factor associated with meeting the entire water heating load is $0.0749(1611 / 21500)$. This value is much less than the load factor that ensures enough time remains to meet the entire space load, $0.8323(1-0.1677)$

If the entire water heating load is satisfied while operating in a water heating only mode (i.e., $x_{\text {wo }}$ determined using the upper of the two options in equation 34 ), the unit switches to a space cooling only mode until the entire building load is satisfied. The entry for the water heating contribution for the water heating only mode (column $R$ ) is the same as column I. The load factor (column M) and the water heating contribution (column $N$ ) for the combined mode are both zero. The load factor for the space cooling only mode is determined by calculating the operating time required for meeting the entire space load,

$$
x_{\text {so }}=B L\left(T_{j}\right) / \dot{Q}_{s o}
$$

The load factor for the water heating only mode, $\mathrm{X}_{\text {}_{0}}$, is typically determined using the upper of the two options in equation 34 . Thus, the calculation sequence described above, water heating only followed by space conditioning only, is much more likely than the other theoretically possible sequences (for sub-bins where water heating begins in a.water heating only mode). This strong likelihood results because of the structure of the proposed bin analysis. Other theoretical sequences are considered if the load factor $X_{w o}$ is determined using the lower of the two options in equation 34. These other sequences include: (1) beginning in a 
water heating only mode and then switching to a combined mode for the remaining portion of the hourly time step; (2) beginning in a water heating only mode, switching to a combined cooling mode, and then if the water heating load is satisfied before the space cooling load, switching to a space cooling only mode; (3) beginning in a water heating only mode, switching to a combined cooling mode, and then if the space cooling load is satisfied before the water heating load, switching back to a water heating only mode for the remaining part of the hourly time step. The last sequence is possible because the calculation logic is set-up to ensure that the building load is satisfied. These other calculation sequences, which are pertinent only if $\mathrm{x}_{\text {wo }}$ is determined using the lower of the two options in equation 34, are described in appendix $A$.

\subsubsection{Calculation of Energy Consumption Rates}

The energy consumption rates of the integrated appliance and the water heater auxiliary elements or burner are calculated using basically the same approach used for heat pump bin calculations [1-5]. To begin, an overall. load factor (column $V$ of Table 7) is calculated by adding the load factors for each operating mode (combined space cooling, space cooling only, and water heating only) in each sub-bin.

$$
\mathrm{X}=\mathrm{X}_{\mathrm{c}}+\mathrm{X}_{\text {wo }}+\mathrm{X}_{\text {so }}(\operatorname{col} \cdot \mathrm{M}+\operatorname{col} \cdot \mathrm{Q}+\operatorname{col} \cdot \mathrm{U})
$$

A part load factor is then determined for each sub-bin using

$$
\mathrm{PLF}=1-\mathrm{C}_{\mathrm{D}}[1-\mathrm{X}] \text {, }
$$

where $C_{D}$ is the cyclic degradation factor. References 1-5 discuss the cyclic tests and the option of using $C_{D}=0.25$ in lieu of testing. For the entries in Table $7, a C_{D}$ of 0.25 is assumed. 
The percentage of the water heating load allocated to the auxiliary. heater (column $Y$ ) is the percentage of the load not allocated to the integrated appliance (column $\mathrm{H}$ ). The water heating load satisfied using auxiliary heat is the product of the total water heating load (column F) and the auxiliary water heating percentage divided by 100 , plus any remaining load that was allocated but not satisfied by the integrated appliance (column $X)$. Only zero entries in column $X$ are expected for integrated appliances having a water heating only mode. For heat pumps having a desuperheater, on the other hand, a portion of the water heating load may remain depending upon the initial allocation of the water heating load based on the recovery test results. In this case, the mechanics of the calculation procedure will play a secondary role in determining the water heating contributions of the integrated appliance and the auxiliary heater.

The energy rates associated with the space cooling loads are calculated given the sub-bin hours, the load factors, and the unit's space cooling capacity in both the space only and combined modes. The energy rates associated with the space cooling and water heating loads are grouped in Table 7 under the heading of weighted loads because the use of fractional bin hours gives weighted averages for the loads. The weighted space load, column AA, is calculated using

$$
q_{s}=m_{j} \cdot\left(x_{c} \cdot \dot{Q}_{c, s}+x_{s o} \cdot \dot{Q}_{s o}\right)
$$

The calculation of the domestic water heating load, column $A B$, provides information as to how the water heating load is distributed among the bins. The calculation step is optional. The weighted load is determined using

$$
q_{w, D H W}=W_{D H W} \cdot m_{j}
$$


where $W_{D B W}$ equals $1702 \mathrm{Btu} / \mathrm{h}$. Finally, the equation for determining the weighted load associated with the water heating contribution of the auxiliary heater is

$$
q_{w, \text { aux }}=\mathrm{wL}_{\text {aux }} \cdot \mathrm{m}_{\mathrm{j}} \text {. }
$$

The energy consumption rates of the integrated appliance for each operating mode are calculated given the sub-bin hours, the load factors, and power usages. As with rating conventional heat pumps [1-5], the part load factor accounts for the performance degradation caused by cycling. The energy consumption rates for each pertinent operating mode are calculated using the following:

$$
\begin{aligned}
& e_{c}=\frac{m_{j} \cdot \dot{E}_{c} \cdot x_{c}}{P L F}, \\
& e_{\text {wo }}=\frac{{m_{j} \cdot \dot{E}_{\text {wo }} \cdot x_{\text {wo }}}_{P L F} \text { and }}{\text { PLF }}
\end{aligned}
$$

As shown in Table 7 , the weighted loads and energy consumption rates for each sub-bin are summed to determine the seasonal values. The sums of columns $A A$ and $A B$ represent the average seasonal building and domestic water heating loads, respectively, that were satisfied. The water heating load associated with the tank standby losses is not included in the entries for column $A B$. The omission of the standby losses is consistent with the calculation of the energy factor of a conventional water heater [6]. The sums of columns $\mathrm{AD}$ to $\mathrm{AF}$ are the seasonal energy consumption rates for the three pertinent operating modes of the integrated appliance during the space cooling season. Finally, the sum of the entries in column AC 
corresponds to the seasonal water heating load met by the auxiliary resistive elements or fossil-fuel burner. For an electric water heater, this seasonal load is converted into a seasonal energy consumption rate using equation 44, where the recovery efficiency $\eta_{R}$ equals 0.98 [6]. A sample calculation for an integrated appliance having an electric water heater is shown at the bottom of Table 7 (page 2). The constant 3.413 is included in the denominator to express $e_{w, r o s}$ in units of watts. For gasfired and oil-fired water heaters, the seasonal rate of fossil-fuel consumption (in units of therms) is calculated using equation 44. In addition, the seasonal energy consumption rate of electrical power by the gas or oil-fired water heater (in units of watts) is estimated using equation 45. The recovery efficiency and the electrical power usage for the controls and the blower, $E_{a u x}$, are taken from the results of the water heater simulated-use test [6].

$$
\begin{aligned}
& \sum e_{w, \text { aux }}=\frac{\sum q_{w, \text { aux }}}{\eta_{R}} \quad \text { (all water heaters) } \\
& \sum e_{w, f o s}=\frac{\sum q_{w, \text { aux }}}{w L_{t}} \cdot \frac{E_{\text {aux }}}{24} \text { (gas and oil-fired units) }
\end{aligned}
$$

The procedures for using these seasonal energy consumption rates to determine a seasonal operating cost and a seasonal performance parameter are described after a brief discussion of the bin calculations for the space heating season.

\subsection{Space Heating Season}

The calculation procedure for the space heating season varies only slightly from the approach used for the space cooling season. Because of the similarities, only the few differences are elaborated. For reference 
purposes, a completed bin calculation worksheet for a variable-speed, integrated $\mathrm{HP} / \mathrm{WH}$ appliance having a space heating only mode, a combined space heating and water heating mode, and a water heating only mode is shown in Table 8 (note: Table 8 continues on a second page).

The fractional bin hours (column C) and the building load (column E) are the same as specified for rating a conventional heat pump [1-5]. The equation for calculating the building load is

$$
\operatorname{BL}\left(T_{j}\right)=\frac{65-T_{j}}{65-T_{D}} \cdot C \cdot D H R
$$

where: $C=0.77$, an experience factor which improves the agreement between the measured and calculated building load,

$$
\begin{aligned}
& T_{D}=\text { the outdoor design temperature }\left({ }^{\circ} \mathrm{F}\right), \text { and } \\
& \mathrm{DHR}=\text { the design heating requirement }(\mathrm{Btu} / \mathrm{h}) .
\end{aligned}
$$

Values for the outdoor design temperature and the fractional bin hour distributions are specified for six different climatic regions [1]. Furthermore, for each climatic region, bin calculations may be conducted using a building load based on a range of standardized design heating requirements. References 1 and 26 describe the building load calculation procedure as a function of the climatic region. The fractional bin hours shown in Table 8 correspond to climatic region IV. The building load is based on region IV and a minimum design heating requirement.

Steady-state capacity and power usage values are assigned for each operating mode as a function of the outdoor temperature. The equations relating capacity and power usage for the space heating only mode are the same as used for a conventional heat pump $[1,3,25]$. Relationships for capacity and power usage versus outdoor temperature for the combined space heating and water heating mode are generated using the approach described 
in section 5.4. (For the combined space heating mode, only desuperheating water heating occurs, not desuperheating and full condensing as is possible with the combined space cooling mode.) The performance equations for the water heating only mode, which were referenced in the space cooling bin calculations, are determined using linear interpolation (refer to Fig. 7). Both the combined mode and water only mode capacity and power usage curves account for the degradation in performance caused by frosting/defrosting as per section 5.4.2.

Bin calculation steps that are the same as described for the space cooling season include (1) the assignment of the sub-bins, (2) the allocation of the total water heating load between the integrated heat pump/water heating appliance and the auxiliary heater, and (3) the logic for calculating the load factors for each operating mode. The weighted water heating loads and the energy consumption rates of the integrated appliance and the water heater auxiliary elements or burner are calculated using the respective equations for the space cooling season, equations 39 through 45. The weighted space heating load is calculated using

$$
q_{s}=B L\left(T_{j}\right) \cdot m_{j}
$$

The typical multiple-mode calculations for each sub-bin are, however, limited to those bins where the maximum space heating capacity of the unit while operating in a combined mode is greater than the building load. When operating below the combined mode balance point in the field, the unit discontinues water heating and gives all available capacity to heating only the space. To mimic this condition in the bin calculation procedure, the entire water heating laad is credited to auxiliary heating and the integrated appliance is evaluated as a conventional heat pump. In Table 8 , the integrated appliance discontinues water heating beginning in the $22^{\circ} \mathrm{F}$ 
outdoor temperature bin. The maximum combined mode space heating capacity of the unit at this temperature, $16670 \mathrm{Btu} / \mathrm{h}$, is less than the building load of $19320 \mathrm{Btu} / \mathrm{h}$.

Finally, the cut-off factor for the integrated appliance (column X) and the weighted power usage for resistive space heating (column AH) are determined using the same procedures as specified for heat pumps [1-5]. These two variables are only pertinent to those bins in which the integrated appliance has discontinued water heating so no special adaptations are required.

\section{METHOD FOR REPORTING PERFORMANCE}

For an integrated appliance having an electric water heater, both a seasonal performance parameter and a seasonal operating cost may be calculated from the results of each bin analysis. An approach for first calculating the seasonal performance parameter and then using it to determine cost is described in the following sub-sections. For an integrated appliance having a gas or oil-fired water heater, operating cost is calculated directly from the results of the bin analysis.

In addition to reporting performance parameters for the appliance when integrated, NIST also recommends stating the SEER and HSPF of the appliance. SEER and HSPF denote the seasonal performance of the integrated appliance if it was used only for space heating and air-conditioning, i.e., no water heating. The seasonal heat pump performance parameters would be calculated using the laboratory data for the space conditioning only modes and the heat pump testing and rating procedures [1-5]. 


\subsection{Combined Performance Factors}

For an all-electric integrated appliance, NIST recommends reporting seasonal and/or annual combined space conditioning and water heating performance factors. Each combined performance factor is the dimensional equivalent $(B t u / W \cdot h)$ of the coefficient of performance associated with the integrated appliance meeting both the seasonal space conditioning and water heating loads. (The option of reporting combined performance factors as dimensionless quantities would be endorsed by NIST.) The combination of performance factors and operating costs providing the most informative yet concise performance summary to the consumer is still under consideration, especially with regard to reporting seasonal versus annual values.

Seasonal combined performance factors are calculated by dividing the summations from the bin analysis for the weighted loads by summations for the energy consumption rates. The combined performance factor for the space cooling (and water heating) season is calculated using

$$
C P F_{c s}=\frac{\sum_{j=1}^{8} q_{s}(j)+\sum_{j=1}^{8} q_{w, D H W}(j)}{\sum_{j=1}^{8} e_{w, r e s}(j)+\sum_{j=1}^{8} e_{c}(j)+\sum_{j=1}^{8} e_{w o}(j)+\sum_{j=1}^{8} e_{s o}(j)} .
$$

The numerator consists of the totals for the building load and the domestic water heating load (columns $A A$ and $A B$, respectively, in Table 7). The denominator includes, in order, the seasonal energy consumption rates of the water heater resistive elements (column $A C$ and equation 44 ) and the integrated appliance while operating in a combined mode (column $A D$ ), a water heating only mode (column $\mathrm{AE}$ ), and a space cooling only mode (column AF). The cooling season combined performance factor for the integrated appliance represented in Table 7 is 


$$
C P F_{C S}=\frac{13102.2+1701.8}{151.3+174.1+53.4+787.6}=12.69 \mathrm{Btu} / \mathrm{w} \cdot \mathrm{h} .
$$

The combined performance factor for the space heating (and water heating) season is calculated using

$$
C P F_{h s}=\frac{\sum_{j=1}^{N} q_{s}(j)+\sum_{j=1}^{N} q_{w, D H w}(j)}{\sum_{j=1}^{N} e_{w, r e s}(j)+\sum_{j=1}^{N} e_{c}(j)+\sum_{j=1}^{N} e_{w o}(j)+\sum_{j=1}^{N} e_{s o}(j)+\sum_{j=1}^{N} e_{r h}(j)},
$$

where $N$ is the number of outdoor temperature bins for the particular climatic region. For region IV, $\mathrm{N}$ equal 15 . The additional term in equation $49, e_{z h}$, is the seasonal energy consumption rate for resistive space heating. Applying equation 49 to the results in Table 8 , the heating season combined performance factor is $7.59 \mathrm{Btu} / \mathrm{W} \cdot \mathrm{h}$.

Although combined performance factors most readily serve as a basis for comparing different integrated appliances (including heat pumps having a desuperheater), the performance descriptors may also be used to compare an integrated appliance with a separate heat pump and water heater. The comparison may be made between the separate components of the integrated appliance or a hypothetical system which would act as a reference of comparison for all integrated appliances.

When comparing against the separate components of the integrated appliance, the results from the bin analyses used to determine the seasonal energy efficiency ratio, SEER, and the heating seasonal performance factor, HSPF, are used. For example, the bin calculation worksheet to determine the SEER of the integrated appliance is shown in Table 9. As should be the case, the seasonal weighted building loads in Table 9 (sum of column I) and Table 7 (sum of column AA) are the same. The seasonal energy consumption rate of the integrated appliance if it operated exclusively in a space 
cooling only mode in meeting the building cooling load is $891.0 \mathrm{~W}$.

Likewise, the energy consumption rate of an electric water heater having an energy factor of 0.88 is $566.6 \mathrm{~W}$ for a water heating load of $1701.8 \mathrm{Btu} / \mathrm{h}$ $\left(Q_{D B W} /\left[E_{f} \cdot 3.413\right]\right)$. Given these quantities, the cooling season combined performance factor of the integrated appliance if the heat pump and water heater were separated is

$$
\mathrm{CPF}_{\mathrm{cs}, \mathrm{sep}}=\frac{13102.2+.1701 .8}{891.0+566.6}=10.16 \mathrm{Btu} / \mathrm{W} \cdot \mathrm{h} .
$$

Thus, as a result of integrating the two separate appliances, the cooling season combined performance factor for the hypothetical system increases from 10.16 to $12.69 \mathrm{Btu} / \mathrm{W} \cdot \mathrm{h}$.

The same calculation could also be made for any reference system of a separate heat pump and electric water heater. For the separate heat pump, the energy consumption rate is determined by dividing the seasonal building load met by the integrated appliance (in this case, $13102.2 \mathrm{Btu} / \mathrm{h}$ ) by the SEER of the reference heat pump. For a heat pump having an SEER of 10, the energy consumption rate in meeting the same space cooling load is $1310.2 \mathrm{~W}$. Assuming the reference electric water heater has an energy factor of 0.88 , as in the above example, the energy consumption rate required to meet the $1701.8 \mathrm{Btu} / \mathrm{h}$ domestic water heating load is again $566.6 \mathrm{~W}$. The cooling season combined performance factor for this reference system is then

$$
\mathrm{CPF}_{\text {cs, sep }}=\frac{13102.2+1701.8}{1310.2+566.6}=7.89 \mathrm{Btu} / \mathrm{w} \cdot \mathrm{h} .
$$

Alternative approaches to using combined performance factors as the basis for comparing an integrated appliance with a separate heat pump and water heater remain under consideration at NIST. One such approach involves deriving separate space cooling and water heating performance factors for the space cooling and water heating season, and similarly, 
separate space heating and water heating performance factors for the space and water heating season. From a thermodynamic standpoint, the main obstacle to doing so stems from not being able to define separate coefficients of performance ( $\left.C O P^{\prime} s\right)$ for times when the integrated appliance operates in a combined mode. For this mode, no way exists for determining how much of the power used by the compressor goes towards conditioning the space versus heating domestic water. If determining separate COP's for the combined mode was possible, then reporting a seasonal space cooling performance factor, a seasonal space heating performance factor, and two seasonal water heating performance factors (which could latter be combined into one) could be better justified. If such performance descriptors could be deduced, they would be given significantly different names than those used for rating heat pumps and water heaters.

The approach described in the prior paragraph would yield seasonal performance parameters for space cooling, space heating, and water heating that differed numerically from the SEER, HSPF, and $E_{f}$ of the separate heat pump and water heater. By comparison, an approach has been proposed where either an "equivalent" SEER (HSPF) is derived by assuming the water heating performance factor of the integrated appliance is equal to the $E_{f}$ of the water heater, or conversely, an "equivalent" $E_{f}$ is derived by assuming the space cooling (heating) performance factor of the integrated appliance is equal to the SEER (HSPF) of the heat pump [9]. The equivalent values may be derived by first calculating the savings associated with having a heat pump and water heater integrated rather than separated. For the example used in this report, the savings are $291.2 \mathrm{~W}([891.0+566.6]-1166.4)$ for the space cooling and water heating season and $168.8 \mathrm{~W}$ during the space and water heating season. These savings are then used to recalculate SEER 
(HSPF) or $E_{f}$. For example purposes, the equivalent values for the hypothetical appliance considered in this report (SEER $=14.71$, HSPF $=$ 8.65, and $E_{f}=0.88$ ) are listed below.

Equivalent Seasonal Space Cooling Performance Factor

$$
=\frac{13102.4}{891.0-291.2}=21.84 \mathrm{Btu} / \mathrm{W} \cdot \mathrm{h}
$$

OR

$$
\begin{aligned}
& \text { Equivalent Seasonal } \\
& \text { WH Performance } \\
& \text { Factor - Cooling }
\end{aligned}=\frac{1702}{(566.6-291.2) \cdot 3.413}=1.81
$$

AND

Equivalent Seasonal Space Heating Performance Factor $=\frac{10747.5}{1242.1-168.8}=10.01 \mathrm{Btu} / \mathrm{W} \cdot \mathrm{h}$

OR

Equivalent Seasonal WH Performance Factor - Heating $=\frac{1702}{(566.6-168.8) \cdot 3.413}=1.25$

As proposed in reference 9, these equivalent values would be differentiated from the conventional parameters by adding a leading "EQ" to the established performance descriptor (e.g., EQSEER).

In its present form, NIST has chosen not to endorse the use of the above approach for reporting performance. Besides the earlier described problem related to deriving separate COP's for an appliance that operates in a combined mode, additional reasons for not endorsing the approach include:

(1) If the equivalent heat pump numbers (EQSEER and EQHSPF) are ever teamed with the equivalent water heater numbers ( $\left.E Q E_{f}\right)$, a "double-dipping" will occur. If operating costs are then calculated using these performance factors, the cost will be under-estimated. 
(2) The practice of crediting performance factors for space conditioning, SEER and HSPF, with the energy savings realized from water heating is inconsistent. In particular, the energy saving that results from heating water in a water heating only mode should be credited to a water heating performance descriptor rather than a space conditioning performance descriptor.

(3) The use of the leading EQ to differentiate the "equivalent" values from the conventional values is not satisfactory. NIST foresees the consumer confusing the two descriptors.

(4) NIST believes that the use of equivalent descriptors could be abused. For example, NIST foresees the consumer being shown the equivalent SEER and HSPF of a unit along with a water heating cost savings. In this case, the consumer may wrongly believe that he gets the low energy costs associated with the high space conditioning performance factors plus a water heating savings.

In general, NIST has hesitations with endorsing an approach where all the savings is given to one appliance versus another. (In fact, the problem worsens if you integrated 3 or more appliances and then gave all the savings credit to one.) If single-function performance factors are needed by manufacturers of integrated appliances so that they can better compare their product against a separate heat pump and water heater, then an attempt should be made to allocate the energy savings from integrating, as correctly as possible, among both the space conditioning and water heating performance descriptors. If the conditions are exceptional such that a way for crediting both appliances is not possible, consideration will be given to using all the saving in adjusting the performance factor that corresponds to the function that has been most improved from integration. NIST will continue to consider the alternatives listed above and any other options that might be proposed for reporting performance.

\subsection{Operating Costs}

Seasonal operating costs for an all-electric integrated appliance may be calculated using an approach which is an adaption of the method used for 
heat pumps [1-5]. A problem, however, arises as a result of using heating and cooling load hours (HLH and CLH) within the calculations. A method for maintaining the use of load hours is described after reviewing how they are used in the cost calculations.

The electrical energy used by the all-electric integrated appliance is determined by dividing the sum of the building and water heating loads for the particular season, expressed in terms of an energy quantity (Btu), by the integrated appliance combined performance factor for the same season. Seasonal cost is then readily calculated given the price of the electricity $(\$ / \mathrm{kWh})$. In equation form, the components of the seasonal cost calculation are

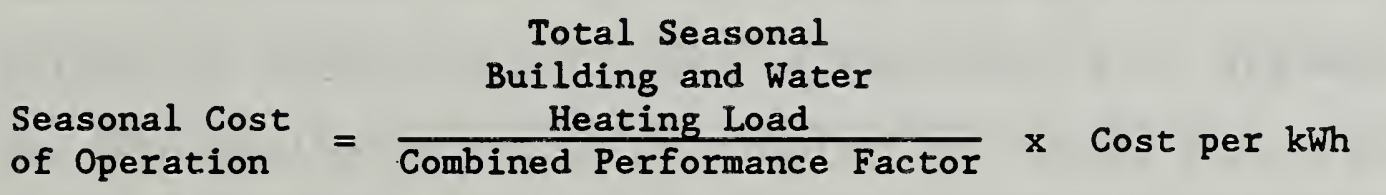

The total seasonal building load referenced in equation 50 is the same as used when rating a conventional heat pump. This load is calculated based on the climatic region and the size of the unit. The space cooling building load is

$$
\begin{aligned}
& \text { Total Space } \\
& \text { Cooling Load }
\end{aligned}
$$

The space heating building load is

Total Space $=$ HLH $\times$ DHR $\times C$,
Heating Load

where DHR and $C$ are the same quantities that are used for calculating the building load for each space heating temperature bin (see equation 46 ). The cooling and heating load hours help account for the climatic variations associated with the different regions of the United States. References 1 and 4 give a map of the continental United States showing the distributions of cooling load hours and a table of the heating load hours for six 
generalized heating season climatic regions. As discussed earlier, fractional bin hour distributions and the basis for calculating space heating building loads are also a function of these heating season climatic regions. The building loads and fractional bin distributions shown in Table 8 are for region IV. For region IV, the number of heating load hours is 2250 , and in addition, the number of cooling load hours typically designated for this region is 800 .

In the seasonal cost calculation, a basis is required for determining how much of the annual domestic water heating load is met during the space heating season and how much is met during the space cooling season. The annual domestic water heating load is $14,909 \mathrm{kBtu}$, which corresponds to a daily usage of 64.3 gallons and a $77^{\circ} \mathrm{F}(135$ - 58) temperature increase. Unfortunately, this load cannot be simply divided between the heating and cooling seasons because the building and water heating loads will not be in the same proportions that they were when used to calculate the combined performance factors. This discrepancy results because the total number of operating hours associated with the seasonal building loads corresponds to less than a full year while the annual water heating load is based on a full, 8760-hour year. Notably, this problem is avoided if actual bin hours, rather than fractional bin hours are used in the bin calculations.

The actual number of hours in the cooling and heating seasons can be derived from the heating and cooling load hours. A derivation by Pietsch [27] showing how to calculate actual hours of operation is given in Appendix B. Table 10 lists the number of hours in the cooling and heating season as a function of the load hours for the six climatic regions $[1,4]$ and the national average values that are often used for rating purposes [28]. The entry in the last column of Table 10 is the difference between 
the number of hours in a year and the sum of the number of hours in the cooling and heating seasons. For all seven cases considered, hours remain where neither space cooling or space heating is depicted as occurring. For labeling purposes, this column of remaining hours is referred to as an inbetween season in Table 10 .

A few options exist for solving the problem associated with using the established heating and cooling load hour combinations. The one receiving the most consideration by NIST is to maintain the use of the established load hour combinations and assume that the typical year consist of three seasons rather than two. The additional season is considered to depict times during the year when only domestic water heating is required. No space conditioning occurs because the building loads are too small to cause the unit to cycle on or the homeowner has switched off the unit. With such an approach, the annual water heating load is divided among the three seasons based on the length of each season. For example, the water heating loads for the space cooling and space heating seasons in region IV are 3811 $(14909 \mathrm{kBtu} \cdot[2239 \mathrm{~h} / 8760 \mathrm{~h}])$ and $9604 \mathrm{kBtu}$, respectively.

Using these allocated water heating loads and equations 50 to 52 , the operating costs for the space conditioning and water heating seasons may be calculated. For the space cooling season having 800 cooling load hours, the estimated cost of operating the integrated appliance depicted in Table 7 is $\$ 209$ if the price of electricity is 8 cents per kilowatt-hour:

$$
\text { Cooling \& WH }=\frac{(800 \mathrm{~h} \cdot 36.73 \mathrm{kBtu} / \mathrm{h})+3,811 \mathrm{kBtu}}{12.69 \mathrm{Btu} / \mathrm{W} \cdot \mathrm{h}} \cdot \frac{\$ 0.08}{\mathrm{kWh}} \text {. }
$$

Similarly for region IV, the estimated operating cost for the space and water heating season is $\$ 740$.

As a result of introducing a third season to the year, the cost for heating water during this season must be determined before an annual 
operating cost can be reported. For a heat pump having a conventional desuperheater, the water heating cost would be the cost associated with meeting the seasonal water heating load using only auxiliary heat since the desuperheater would not be contributing. For an integrated HP/WH appliance having a water heating only mode, however, an additional bin analysis is required. An attempt at such an analysis is depicted by the completed worksheet in Table 11. The calculation steps for completing this worksheet are a subset of the steps described in section 6.1 .2 for sub-bins that begin in a water heating only mode. The range of bin temperatures used is the analysis, column $A$, and the distribution of the bin hours, column $B$, are two key parts where more work is needed. The entries for these two columns are given only for example purposes.

The cost of water heating during the in-between season is determined by first calculating a seasonal performance factor, which for the results in Table 10 is $5.62 \mathrm{Btu} / \mathrm{W} \cdot \mathrm{h}(1702 / 302.6)$. Cost is determined by dividing the water heating load associated with the length of the in-between season by the performance factor and then multiplying the quotient by the cost of the electrical energy. For the example used here, the cost is

$$
\text { WHO Costs }=\frac{(878 \mathrm{~h} / 8760 \mathrm{~h}) \cdot 14909 \mathrm{kBtu}}{5.62 \mathrm{Btu} / \mathrm{W} \cdot \mathrm{h}} \cdot \frac{\$ 0.08}{\mathrm{kWh}}=\$ 21 .
$$

The annual operating cost can now be determined by adding the three seásonal values.

The equation for calculating an annual combined performance factor was purposely omitted in section 7.1 so that the condition of having a third season could be first introduced. An annual value is calculated using

$$
\mathrm{ACPF}=\frac{\mathrm{AWHL}+\mathrm{ASHL}+\mathrm{ASCL}}{\frac{\mathrm{AWHL} \cdot \frac{\mathrm{ISH}}{8760}}{\mathrm{CPF}_{\text {is }}}+\frac{\mathrm{ASHL}+\mathrm{AWHL} \cdot \frac{\mathrm{HSH}}{8760}}{\mathrm{CPF}_{\mathrm{hs}}}+\frac{\mathrm{ASCL}+\mathrm{AWHL} \cdot \frac{\mathrm{CSH}}{8760}}{\mathrm{CPF}_{\mathrm{CS}}}},
$$


where: AWHL is the annual water heating load $(14,909 \mathrm{kBtu})$,

ASHL is the annual space heating load as defined by equation 52 , ASCL is the annual space cooling load as defined by equation 51 , the CPF's are the combined performance factors for each season, and ISH, HSH, and CSH are the number of hours in each season, Table 10. For the hypothetical system used in examples throughout the report, the annual combined performance factor for region IV is $8.65 \mathrm{Btu} / \mathrm{w} \cdot \mathrm{h}$.

Briefly, with regards to integrated heat pump/water heating appliances having a gas or oil-fired water heater, the seasonal costs may be calculated by using the energy consumption rates from the bin worksheets and the data given in Table 10 on the number of hours in each season as a function of the climatic region. The energy consumption rates for a particular season are multiplied by the corresponding number of hours in the season to get the totals for the electrical and the fossil-fuel energy used. The respective totals are then multiplied by the price of the electricity and the fossil-fuel to get a seasonal operating cost.

In summary, the annual and seasonal operating costs provide an understandable basis for comparing a particular integrated appliance with other separate and integrated appliances that provide the same space conditioning and water heating functions. For comparisons with conventional heat pumps, the annual (or seasonal) water heating cost associated with using a specific electric water heater would be added to the estimated annual (or seasonal) cost for operating the heat pump. A water heater having an energy factor matching the DoE minimum standards $(0.87)$, is recommended for making the comparison. By comparing the operating costs, the benefits of the integrated appliance are clearly shown and understood. 


\section{ACKNOWLEDGEMENTS}

The project was co-sponsored by the Electric Power Research Institute (EPRI Contract No. RP2033-26) and the U.S. Department of Energy, Office of Conservation and Renewable Energy. The Carrier Corporation, especially Dr. Charles Bullock, and the EPRI are acknowledged for sharing valuable information on the developing technology of integrated heat pump/water heating appliances. Information, assistance and insight were gained from many other sources, including members of the DoE Equipment Division, members of ASHRAE Standards Project Committee 137P, and numerous NIST personnel, especially Stephen Petersen and Dr. A. Hunter Fanney. Flora Parsons, of the NIST Heat Transfer group, is also acknowledged for her assistance in preparing the manuscript. 
1. Department of Energy, "Test Procedures for Central Air Conditioners, Including Heat Pumps," Federal Register, Vol. 44, No. 249, pp. 76700 76723, U.S. Government Printing Office, Washington, DC, December 27 , 1979.

2. American Society of Heating, Refrigerating, and Air-Conditioning Engineers, Inc., "ANSI/ASHRAE Standard 116-1983 Methods of Testing for Seasonal Efficiency of Unitary Air-Conditioners and Heat Pumps," Atlanta, GA, 1983.

3. Department of Energy, "Final Rulemaking Regarding Test Procedures for Central Air Conditioners, Including Heat Pumps, "Federal Register, Vol. 53, No. 49, pp. 8304-8319, U.S. Government Printing Office, Washington DC, March 14, 1988.

4. Air Conditioning and Refrigeration Institute, "ARI Standard 210/24084 Standard for Unitary Air-Conditioners and Air-source Heat Pump Equipment," Arlington, VA, 1984.

5. Code of Federal Regulations, Title 10, Part 430, Washington D.C., 1985 .

6. Department of Energy, "Notice of Proposed Rulemaking and Public Hearing Regarding Energy Conservation Standards for Water Heaters," Federal Register, Vol. 54, No. 10, pp. 1890-1910, U.S. Government Printing Office, Washington, DC, January 17, 1989.

7. American Society of Heating, Refrigerating, and Air-Conditioning Engineers, Inc., "Proposed ASHRAE Standard 118.2P Methods of Testing for Rating Residential Water Heaters," Atlanta, GA, (in review).

8. Cook, R. E., Davidson, M. J., D'Valentine, M., and Goldschmidt, V. W., "A Simple Method to Determine the Yearly Consumption of a Combined Space- and Water-Heating Appliance with a Heat Pump and Desuperheater, " ASHRAE Transactions, V. 92, Pt. 2, 1986, pp. 399-414.

9. Department of Energy, "Petition for Waiver and Application for Interim Waiver of Central Air Conditioners and Heat Pump Test Procedures From Carrier Corporation (Case CAC-005)," Federal Register, Vol. 54, No. 150, pp. 32372-32376, U.S. Government Printing Office, Washington, DC, August 7, 1989.

10. American Society of Heating, Refrigerating, and Air-Conditioning Engineers, Inc., "Methods of Testing for Efficiency of SpaceConditioning/Water-Heating Appliances that Include a Desuperheater Water Heater," ASHRAE Standards Project Committee 137P, (in development).

11. Air Conditioning and Refrigeration Institute, "ARI Standard 290P for Air-Conditioning and Heat Pump Equipment Incorporating Potable Water Heating Devices," (in development). 
12. Dougherty, B. P., "Monitoring of a Residential Desuperheater Water Heater. Monitoring Period: 5 Days in January, "Unpublished Letter Report Prepared for ASHRAE Standards Project Committee 137P, National Institute of Standards and Technology, Gaithersburg, MD, January 1989.

13. Dougherty, B. P., "Thermostat Characteristics of Two Dual-Element Electric Water Heaters when the Lower Thermostat is Set to $110^{\circ} \mathrm{F}$, " Unpublished Letter Report Prepared for ASHRAE Standards Project Committee 137P, National Institute of Standards and Technology, Gaithersburg, MD, January 1989.

14. Petersen, S. R., HPEAK (Heat Pump/Economic Analysis of RilowattHours) Users Guide, Distributed by the Electric Power Research Institute (contact: John Kesselring).

15. Cook, R. E., verbal communication at first meeting of ASHRAE Standards Project Comittee 137P, Ottawa, Ontario, June 27, 1988.

16. Crawford, J. or Trane Co., Tyler, TX, presentation of laboratory performance data at second meeting of ASHRAE Standards Project Committee 137P, Chicago, IL, Jan. 30, 1989.

17. Goldschmidt, V. W., "Desuperheater \& Air-to-Air Heat Pump System: Representative Performance Data," Draft copy released to ASHRAE SPC$137 \mathrm{P}$ committee members prior to third meeting of committee, Vancouver, British Columbia, June 26, 1989.

18. Kesselring, J. of the Electric Power Research Institute, presentation of field results on a prototype integrated heat pump/water heating appliance, EPRI Electric Utility Interest Group Meeting, May 10, 1989, Atlanta, GA.

19. Carrier Corporation personnel with most recent communication with Bullock, C. E., Syracuse NY, private communication, May 1, 1989.

20. Wethje, L. of ETL Laboratories, and Fanney, A. H. of the National Institute of Standards and Technology, private communications, February 1989 .

21. Dave Hogue of Therm-O-Disc, Inc., Mannsville, OH, private comunication, June 13, 1989.

22. ASHRAE Handbook -- HVAC Systems and Applications, Chapter 54, p. 54.10, American Society of Heating, Refrigerating and AirConditioning Engineers, Inc., Atlanta, GA, 1987.

23. American Society of Heating, Refrigerating, and Air-Conditioning Engineers, Inc., "ANSI/ASHRAE Standard 37-1988 Methods of Testing for Rating Unitary Air-Conditioning and Heat Pump Equipment," Atlanta, GA, 1988 . 
24. Urbs, D. G., Bullock, C. E., and Voorhis, R. J., "New Testing and Rating Procedures for Seasonal Performance of Heat Pumps with Variable Speed Compressors," ASHRAE Transactions, Vol. 92, Part 2, 1986.

25. Domanski, P. A., "Recommended Procedure for Rating and Testing of Variable Speed Air Source Unitary Air Conditioners and Heat Pumps," NBSIR 88-3781, National Bureau of Standards, U.S. Department of Commerce, Gaithersburg, MD, May 1988.

26. Parken, W. H., Kelly, G. E., and Didion, D. A., "Method of Testing, Rating, and Estimating the Heating Seasonal Performance of Heat Pumps," NBSIR 80-2002, National Bureau of Standards, April 1980.

27. Pietsch, J. , Private Consultant and Chairman of ASHRAE Standards Project Committee 137, Dallas, TX, private communication, June 26, 1989.

28. Air-Conditioning and Refrigeration Institute, "ARI Unitary Directory August 1989 - January 1990," Arlington, VA.

29. Kelly, G. E., and Parken, W. H. Jr., "Method of Testing, Rating, and Estimating the Seasonal.Performance of Central Air-Conditioners and Heat Pumps Operating in the Cooling Mode," NBSIR 77-1271, National Bureau of Standards, April 1978.

30. McConnell, R. R., Tobias, J. R., and Nelson, L. W., "Reducing Energy Consumption During the Cooling Season," ASHRAE Journal, June 1976, pp. 61-65.

31. Kelly, G. E., of the National Institute of Standards and Technology, Gaithersburg, MD, private communication, September 14, 1989.

32. Tobias, J. R., Nelson, L. W., and McConnell, R. R., "Reducing Energy Consumption During the Cooling Season -- An Analog Computer Study," Internal Report of Honeywell Inc., Report No. 70-6245, September 1974, 13 pages. 
10. APPENDIX A. Load Factor Calculations: Additional calculation sequences for sub-bins where water heating begins in a water heating only mode.

In section 6.1 .2 of the main text, the most likely load factor calculation sequence is described for sub-bins where water heating begins in a water heating only mode. This most likely sequence involves beginning in a water heating only mode and then switching to a space cooling only mode. As mentioned in section 6.1 .2 , other theoretically possible sequences exist. These other possibilities are detailed in this appendix.

If the entire water heating load cannot be met while operating in a water heating only mode (i.e., $x_{\text {wo }}$ is determined using the lower of the two options in equation 34 ), the unit switches to a combined space cooling mode. The combined mode is assumed to follow the water heating only mode even though the maximum space load factor [ $X_{\max }$, equation 29] may have been calculated using capacity for the space cooling only mode. By limiting the water heating only mode based on $X_{\max }$, the space cooling load is ensured of being satisfied and the tendency of the unit to heat water if the available capacity exists is preserved.

The load factor for the combined mode (column $M$ of Table 7 ) is determined by comparing which load, the remaining water heating load or the entire space cooling load, is satisfied first,

$$
x_{c}=\quad \begin{gathered}
B L\left(T_{j}\right) / \dot{Q}_{c, s} \\
\text { or } \\
\left(W L_{h p, \max }-W L_{h p, w o}\right) / \dot{Q}_{c, w}
\end{gathered}
$$


whichever is smaller. The water heating load met while operating in the water heating only mode, a quantity needed to solve the lower of the two options for equation 54 , is determined from

$$
\mathrm{WL}_{\mathrm{hp} \text {, wo }}=\mathrm{x}_{\text {wo }} \cdot \dot{\mathrm{Q}}_{\text {wo }} \text {. }
$$

If the water heating load is met first (i.e., $x_{c}$ is smaller for the lower of the two options in equation 54), the unit switches to a space cooling only mode until the remaining space load is satisfied. The load factor for the space cooling only mode is calculated using equation 31. The water heating contribution for the combined mode (column $N$ ) equals

$$
W_{h p, c}=x_{c} \cdot \dot{Q}_{c, w} \text {, }
$$

and the water heating only mode contribution (column $R$ ) is the value calculated using equation 55 .

If the space cooling load is met first (i.e., $X_{c}$ is smaller for the upper of the two options in equation 54) and the bin hourly time step has not been exceeded, the fractional time spent in the water heating only mode, and therefore the water heating contributed by the integrated appliance while operating in this mode, is adjusted. The fractional time remaining during the hour is

$$
x_{r e}=1-\left[x_{c}+x_{\text {wo }}\right] \text {, }
$$

where $X_{c}$ and $X_{n}$ o are calculated using equations 54 and 34 , respectively.

A zero value for $\mathrm{x}_{\mathrm{r} \text { e }}$ indicates that the unit did not have any additional time for heating water. The remaining portion of the water heating load allocated to the integrated appliance is assumed to be recovered using auxiliary heat. This remaining water heating load (column $\mathrm{X}$ ) is calculated using

$$
W L_{h p, r e}=W L_{h p, \max }-\left(W L_{h p, w o}+W L_{h p, c}\right) \text {, }
$$


where the water heating contributions $\mathrm{WL}_{\mathrm{hp}, \text { no }}$ (column $\mathrm{R}$ ) and $\mathrm{WL}_{\mathrm{hp}, \mathrm{c}}$ (column N) are calculated using equations 55 and 56, respectively. The load factor for the water heating only mode (column Q) is the value determined using equation 34.

If $\mathrm{X}_{\mathrm{r}}$. is not equal to zero, corrections are made for the time spent and the water heating contributed while the unit operated in a water heating only mode. Specifically, the quantities $\mathrm{X}_{\text {wo }}$ and $\mathrm{WL}_{\mathrm{h} p, \text { wo }_{0}}$ are adjusted based on whether the remaining water heating load is satisfied within the remaining fractional time.

$$
\begin{aligned}
& {\left[w_{h p, \max }-\left(w L_{h p, w o}+w L_{h p, c}\right)\right] / \dot{Q}_{w o}} \\
& x_{\text {wo, re }}= \\
& \text { or } \\
& \mathrm{X}_{r e} \text {, whichever is smaller. }
\end{aligned}
$$

The corrected load factor for the water heating only mode (column Q) is

$$
x_{\text {wo }}=x_{\text {wo }}+x_{\text {wo, }, r e}
$$

where the value of $\mathrm{X}_{\text {wo }}$ on the right-hand side of the equation is taken from equation 34 .

If the upper option of equation 59 applies, the entire water heating load allocated to the integrated appliance is satisfied. Conversely, if the lower option of equation 59 applies, part of the allocated water heating load is assumed to be recovered by the auxiliary heater. For both cases, however, the water heating contributed while operating in a water heating only mode (column $R$ ) is determined from equation 55, only now using the corrected load factor from equation 60 . If applicable, the water heating load not met by the integrated appliance is calculated using equation 58 . 
11. APPENDIX B. Derivation of equations for determining the length of the space conditioning seasons

Cooling and heating load hours (CLH and HLH) are used to calculate annual space heating and cooling loads which, in turn, are used to determine seasonal heat pump operating costs [1-5]. Cooling load hours are the number of hours required to meet the annual building cooling load $\left(65^{\circ} \mathrm{F}\right.$ base) if the heat pump cooling capacity was constant and equal to its capacity at the outdoor design temperature, and if applicable, maximum compressor speed $[29,30]$. Cooling load hours account for a 10 per cent oversizing of the heat pump at design conditions [31]. The basis for the now familiar cooling load hour map $[1,2,4,5,29]$ stems from the results of a study using bin weather data for 205 weather stations throughout the United States [32]. In a similar manner, heating load hours are the number of hours required to meet the annual building space heating load $\left(65^{\circ} \mathrm{F}\right.$ base) if the heat pump heating capacity was constant. Heat pump heating capacity, in this case, is defined in terms of the design heating requirement, DHR. For a given location, the heating load hours are determined given the outdoor design temperature and the number of heating season degree-days [26]. For clarity, however, load hours are not the number of hours in either the space cooling or space heating seasons. These seasons include times when the building is gaining or losing heat but the HVAC equipment is intermittently off.

The length of the cooling and heating seasons can be calculated using the data from seasonal heat pump bin analyses and a specification of the heating and cooling load hours. Leaving the mathematical derivation for latter, the number of hours in a season can be quickly calculated from the 
final results of a heat pump bin calculation and the heat pump operating cost equation. The steps are as follows.

1) From the bin analysis, the weighted-average building load for the season is calculated. Conventionally, this load is then used to calculate either SEER or HSPF, but is otherwise neither used nor reported. Referring to the bin worksheet in Table 9, the weightedaverage space cooling load is $13102.4 \mathrm{Btu} / \mathrm{h}$.

2) In determining heat pump operating costs, the total building loads are calculated for the cooling season, equation 51 , and the space heating season, equation 52 (repeated below). For the space cooling only integrated appliance depicted in Table 9, its space cooling capacity at $95^{\circ} \mathrm{F}$ and maximum compressor speed is 36,730 Btu/h. Using region IV ( 800 cooling load hours) as an example, the total building cooling load is determined to be 29,384,000 Btu.

3) The total building cooling load could have been determined directly from the bin calculations if actual hours had been used instead of fractional hours (column $C$ in Table 9). The actual number of hours, however, can be calculated after-the-fact by dividing the total building load used in the cost calculation (step 2) by the weighted-average building load from the bin analysis (step 1). The result, 2242.6 hours, is the number of hours in the cooling season for a location having 800 cooling load hours.

A point worth noting is that 2239 hours are reported in Table 10 for the length of the cooling season having 800 cooling load hours. By comparison, the sample calculation yielded 2243 hours. The discrepancy results because the entries in Table 10 are based on the derived equation for the cooling season given below. This derived equation gives the same results as the calculation steps described above if the entire building load is met by the heat pump as part of the bin calculations. Referring to the bin worksheet (Table 9), the discrepancy is directly linked to those bins where the cooling capacity of the heat pump, column E, is insufficient to meet the building load, column D. Usually, this condition only occurs for the $102^{\circ} \mathrm{F}$ temperature bin and so only has a minimal effect on the final calculation of the hours in a season. Notably, such discrepancies will only occur for the space cooling season. For the space heating season, the problem is avoided because the entire building load is always met as part 
of the bin analysis. Electric resistance heat is assumed to compensate for times when the heat pump lacks the space heating capacity to meet the building load.

The mathematics behind the above sample calculation are shown below. Expressing the relationship in mathematical terms was first done by Pietsch [27].

Starting with the heating season, the annual space heating load, ASHL, can be determined two ways: (1) using the numerator of the seasonal operating cost calculation, equation 52, and (2) using the seasonal bin calculations if the number of operating hours during the season are specified, equation 61.

$$
\begin{aligned}
\text { ASHL } & =\text { HLH } \times \text { DHR } \times C \\
\text { ASHL } & =\sum_{j=1}^{N} \frac{\left(65-T_{j}\right)}{\left(65-T_{D}\right)} \cdot \text { DHR } \cdot C \cdot\left(n_{j} \cdot H S H\right)
\end{aligned}
$$

The variable HSH is used to designate the heating season hours, i.e., the number of hours in the heating season. The heating season hours are distributed among the total number of temperature bins, $N$, according to the fractional bin hours, $n_{j}$. Since the design heating requirement, DHR, the experience factor which improves the agreement between measured and calculated building loads, $C$, the heating season design temperature, $T_{D}$, and the heating season hours are all constants, equation 61 may rewritten as follows.

$$
\text { ASHL }=\frac{(D H R \cdot C \cdot H S H)}{\left(65-T_{D}\right)} \cdot \sum_{j=1}^{N}\left(65-T_{j}\right) \cdot n_{j}
$$

An expression for the heating season hours, equation 62 , is derived by equating equations 52 and 61. 


$$
H S H=\frac{H L H \cdot\left(65-T_{D}\right)}{\sum_{j=1}^{N}\left(65-T_{j}\right) \cdot n_{j}}
$$

This equation was used to calculate the entries in Table 10 ;

In a similar fashion, an equation for the cooling season hours, CSH, can be derived. The three key equations of the derivation are given below.

$$
\text { ASCL }=\text { CLH } \times \dot{Q}_{S O}(95) \text {. }
$$

$$
\begin{aligned}
& \text { ASCL }=\frac{\left[\dot{Q}_{S O}(95) \cdot C S H\right]}{1.1 \cdot(95-65)} \cdot \sum_{j=1}^{8}\left(95-T_{j}\right) \cdot n_{j} \\
& C S H=\frac{C L H \cdot 1.1 \cdot(95-65)}{\sum_{j=1}^{8}\left(T_{j}-65\right) \cdot n_{j}}
\end{aligned}
$$


Table 1. Typical Residential Usage of Hot Water/Task

\begin{tabular}{lrrrrr}
\hline \multicolumn{1}{c}{ Use } & High Flow & \multicolumn{2}{c}{$\begin{array}{c}\text { Low Flow } \\
\text { (Water } \\
\text { Savers Used) } \\
\text { gal }\end{array}$} \\
\hline Food preparation & gal & L & 3 & $(11)$ \\
Hand dishwashing & 5 & $(19)$ & 4 & $(15)$ \\
Automatic dishwasher & 4 & $(15)$ & 15 & $(57)$ \\
Clothes washer & 15 & $(57)$ & 21 & $(80)$ \\
Shower or bath & 32 & $(121)$ & 15 & $(57)$ \\
Face and hand washing & 20 & $(76)$ & 2 & $(7.2)$ \\
\hline
\end{tabular}

(Reprinted by permission from the ASHRAE Handbook--1987 HVAC Volume) 


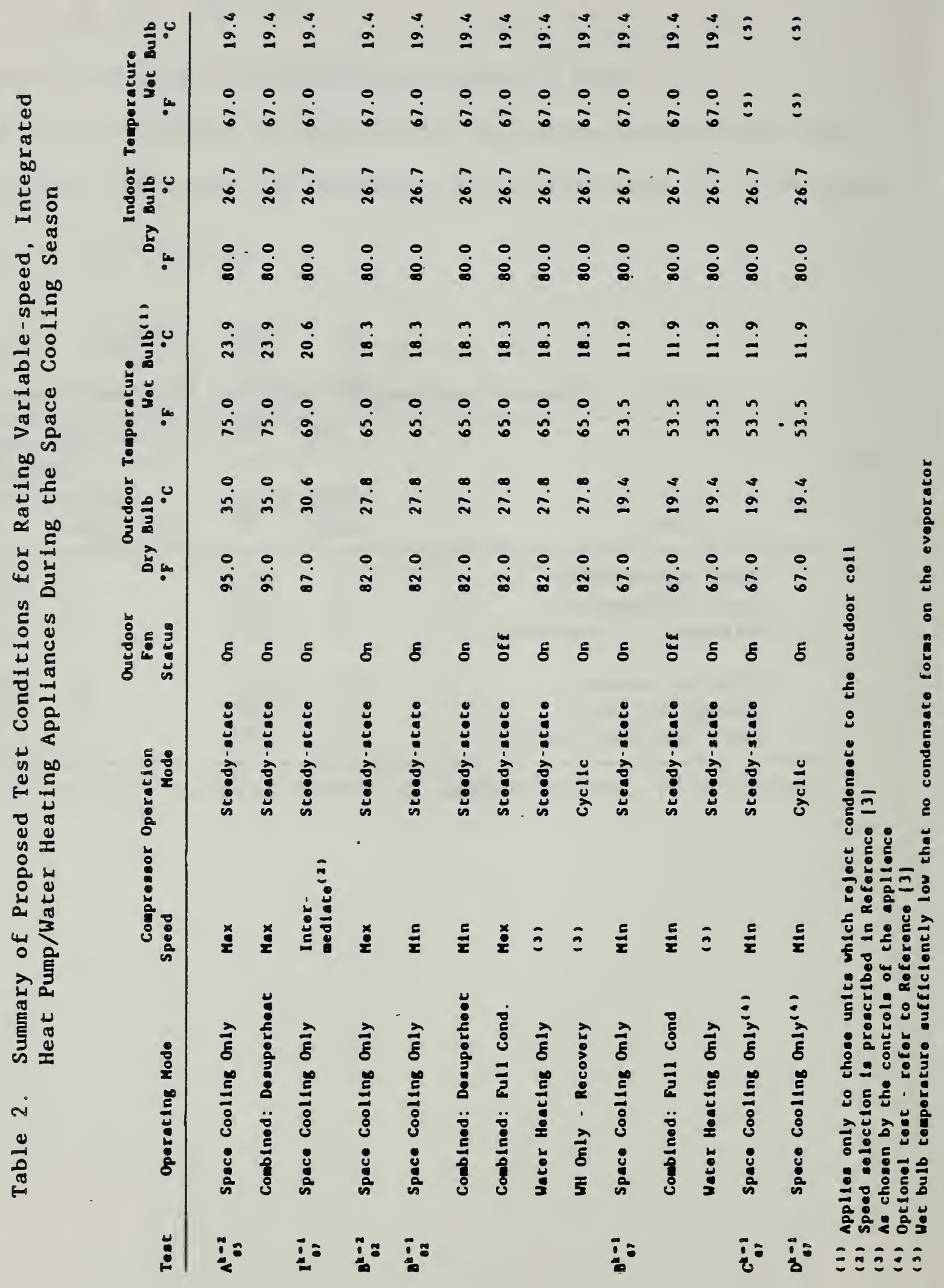




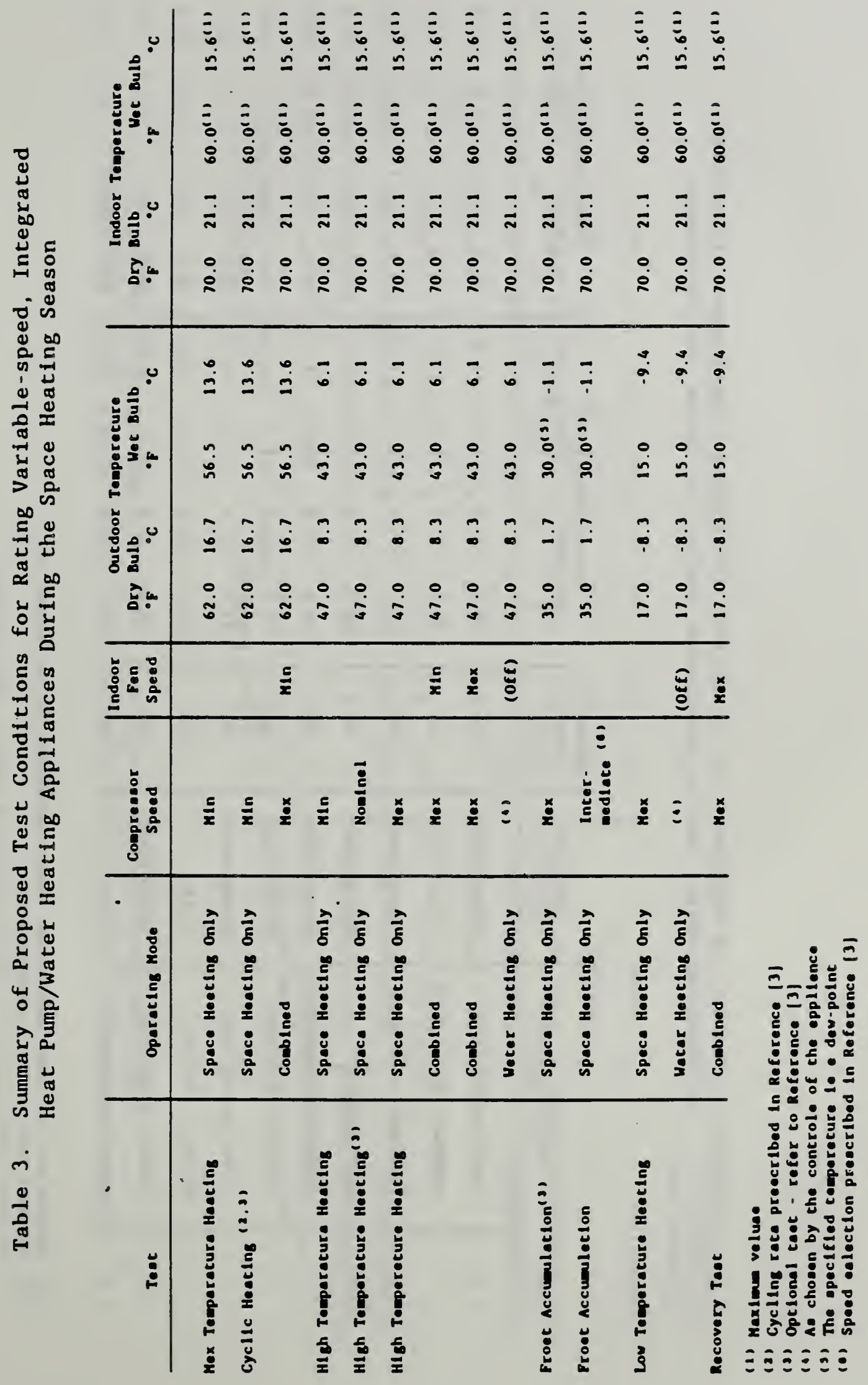




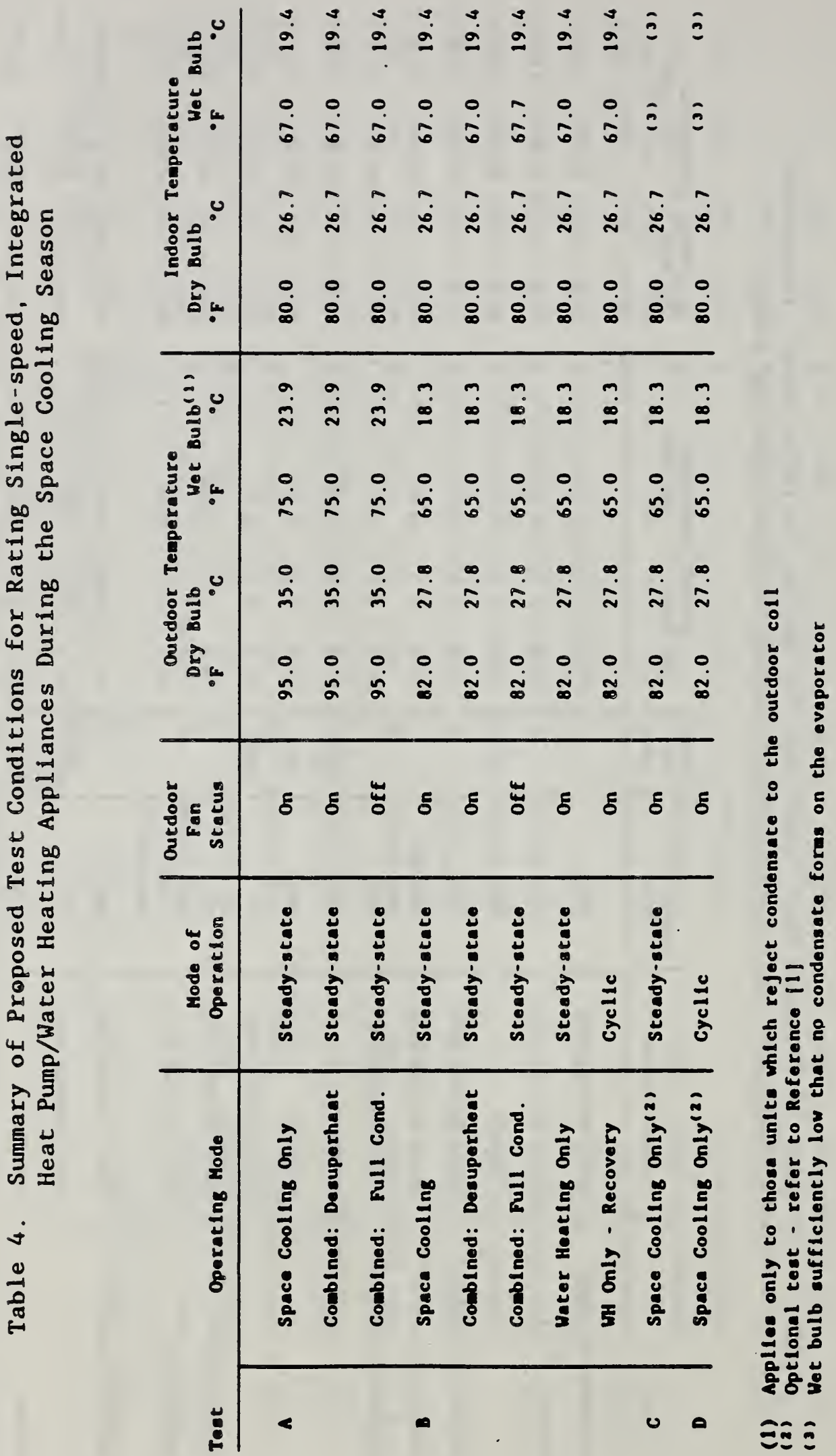




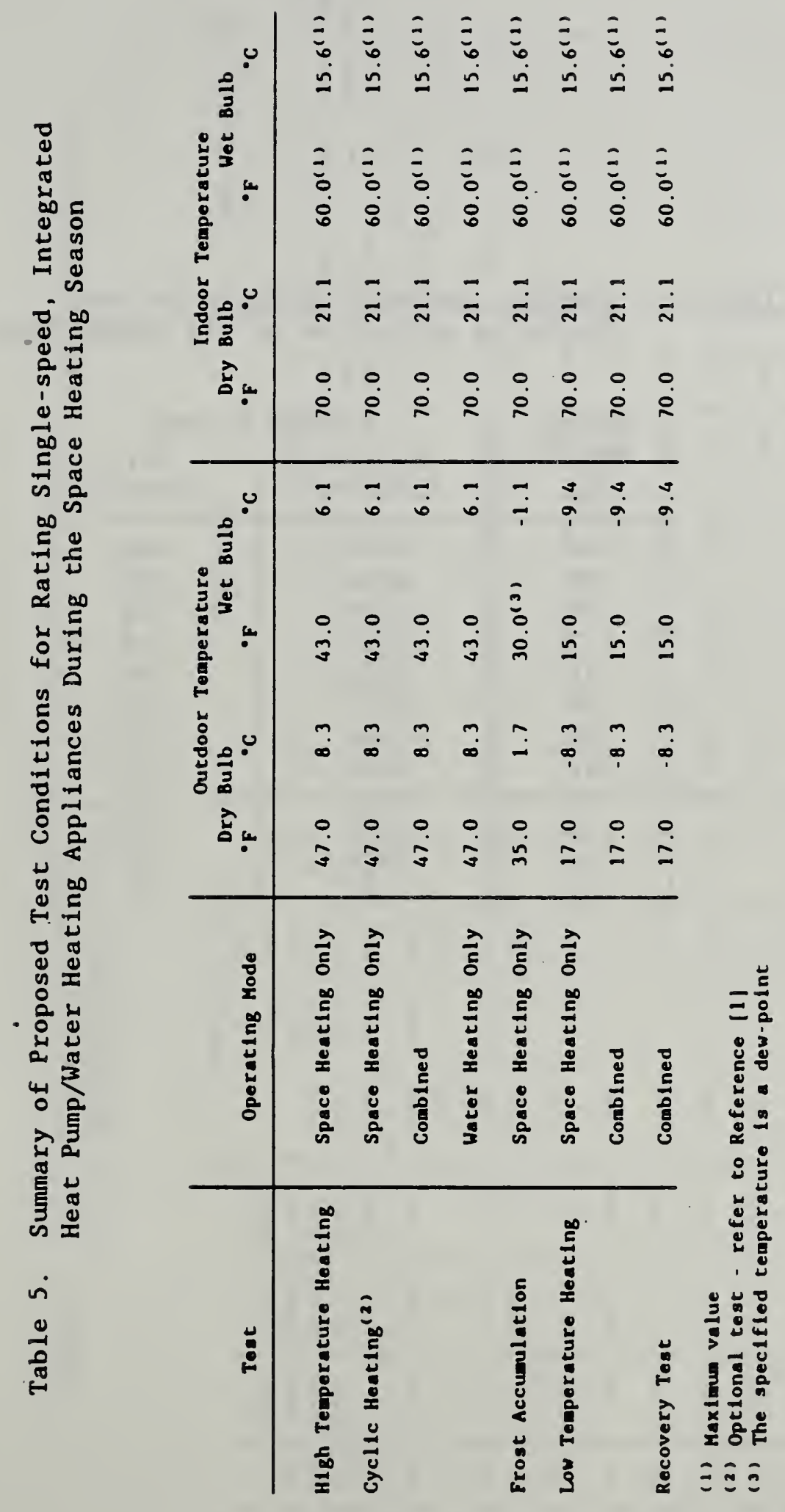


Table 6. Standby Losses of an Electric Water Heater as a Function of its Energy Factor

\begin{tabular}{|c||c|c|}
$\begin{array}{c}\text { Energy } \\
\text { Factor } \\
E\end{array}$ & $\begin{array}{c}\dot{Q}_{t k} \\
\text { (Btu/day) }\end{array}$ & $\begin{array}{c}\dot{Q}_{t k} \\
(B t u / h)\end{array}$ \\
\hline .84 & 6810 & 284 \\
.85 & 6248 & 260 \\
.86 & 5700 & 238 \\
.87 & 5165 & 215 \\
.88 & 4640 & 193 \\
.89 & 4131 & 172 \\
.90 & 3630 & 151 \\
.91 & 3142 & 131 \\
.92 & 2660 & 111 \\
.93 & 2196 & 92 \\
.94 & 1740 & 72 \\
.95 & 1290 & 54
\end{tabular}


Uี

$=-=-$
0

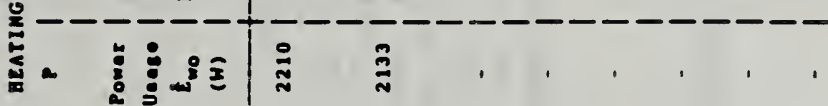

-

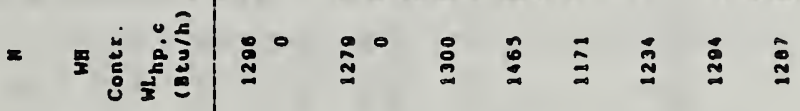

=

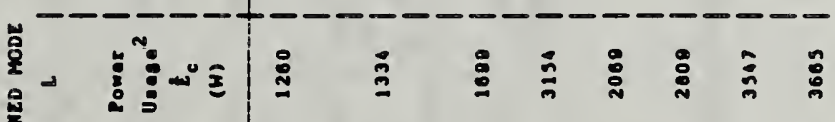

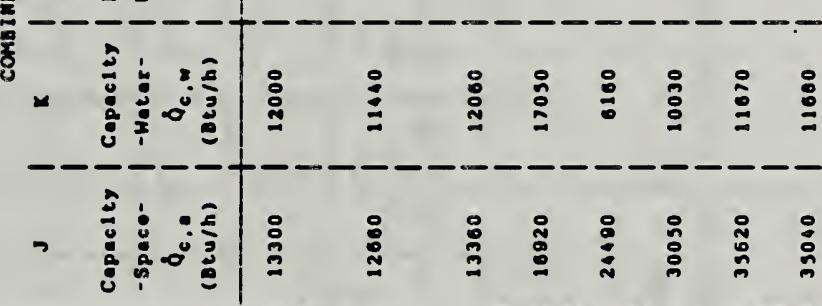

i. 0

-

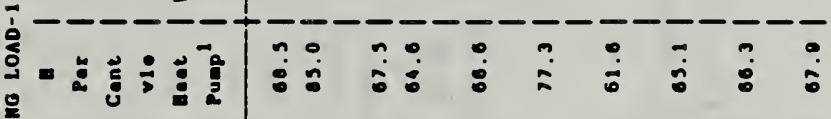




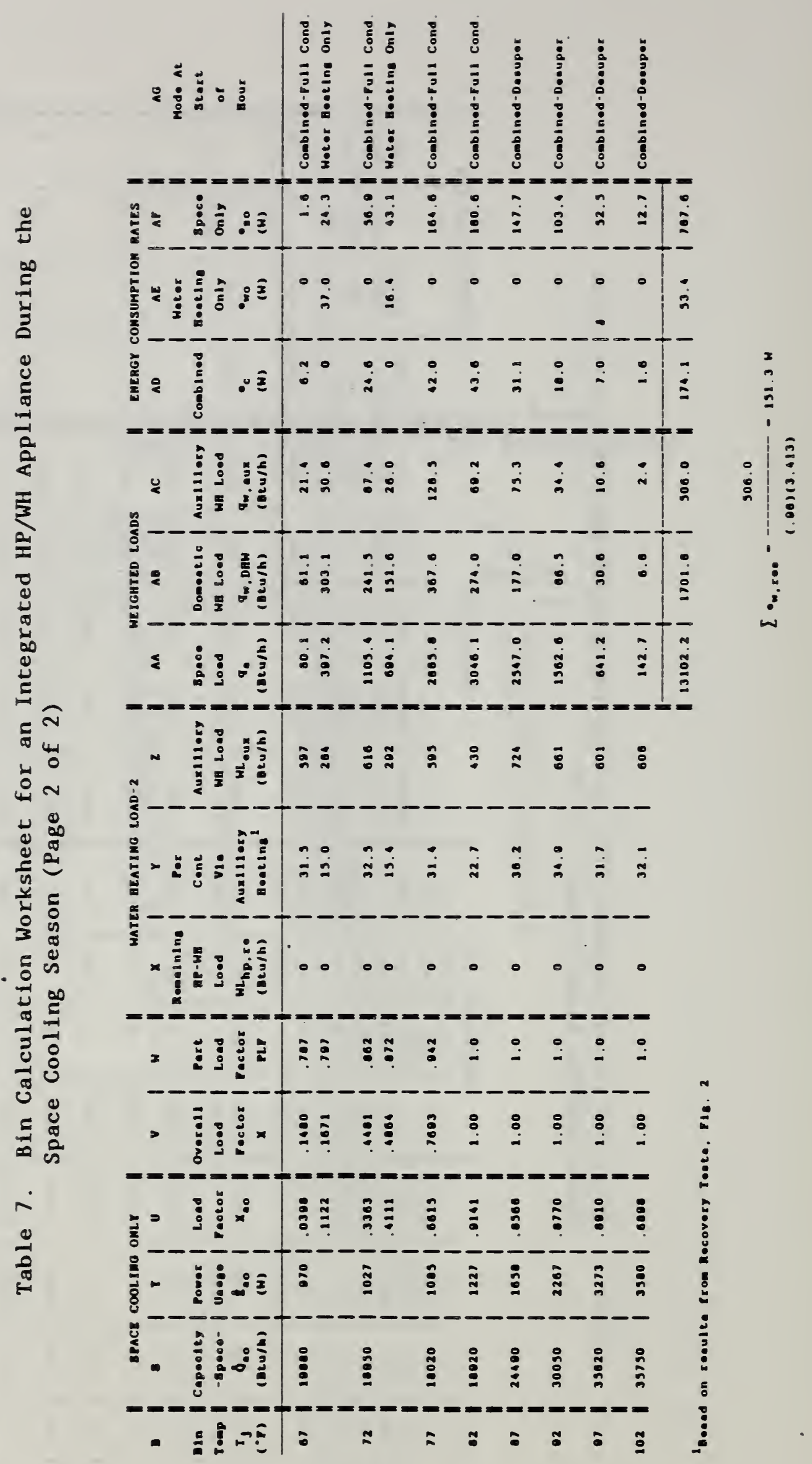




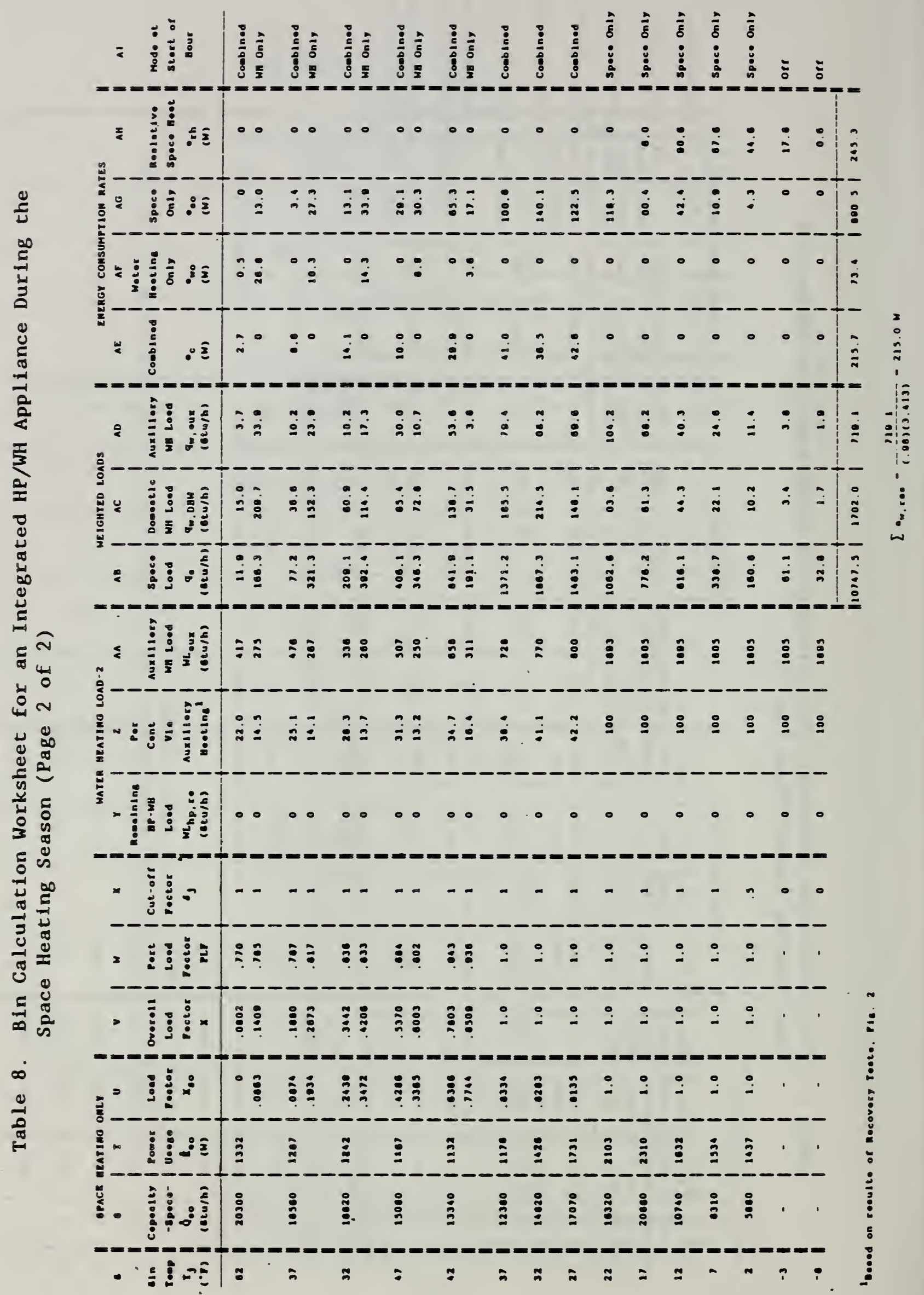




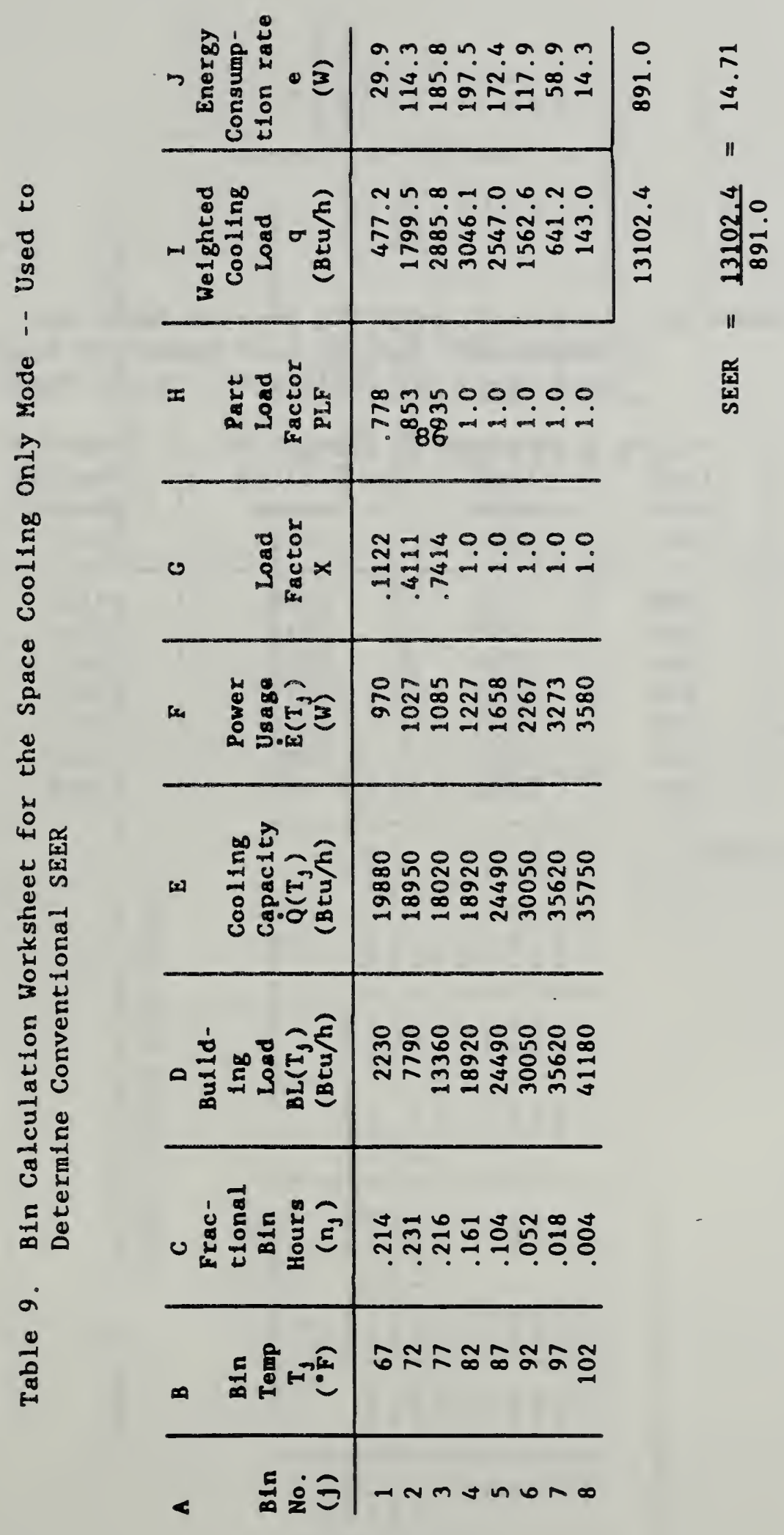


Table 10. Length of Operating Seasons Based on Established Cooling Load Hours and Heating Load Hours for Different Climatic Regions

\begin{tabular}{c|c|c|c|c|c} 
Climatic & $\begin{array}{c}\text { Cooling } \\
\text { Load } \\
\text { Hoursion } \\
\text { CLH }\end{array}$ & $\begin{array}{c}\text { Heating } \\
\text { Load } \\
\text { Hours } \\
\text { HLH }\end{array}$ & $\begin{array}{c}\text { Length of } \\
\text { Cooling } \\
\text { Season } \\
\text { (hr) }\end{array}$ & $\begin{array}{c}\text { Length of } \\
\text { Heating } \\
\text { Season } \\
\text { (hr) }\end{array}$ & $\begin{array}{c}\text { Length of } \\
\text { In-Between } \\
\text { Season } \\
\text { (hr) }\end{array}$ \\
\hline I & 2400 & 750 & 6718 & 1826 & 216 \\
II & 1800 & 1250 & 5038 & 3148 & 574 \\
III & 1200 & 1750 & 3359 & 4453 & 948 \\
IV & 800 & 2250 & 2239 & 5643 & 878 \\
Rating Values & 1000 & 2080 & 2799 & 5216 & 745 \\
V & 400 & 2750 & 1120 & 6956 & 684 \\
VI & 200 & 2750 & 560 & 6258 & 1942
\end{tabular}

${ }^{1}$ Refer to Reference 4 


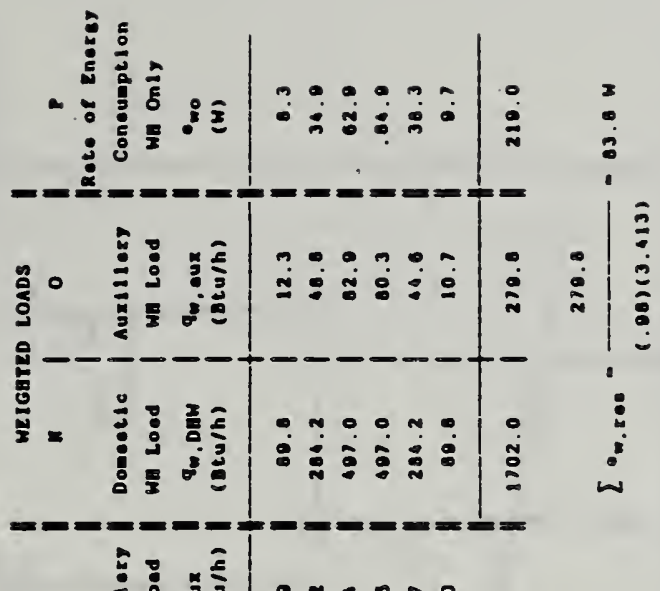

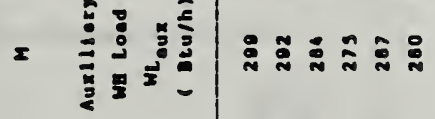

乌ั่

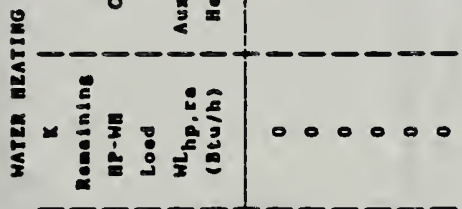

,

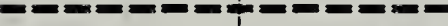

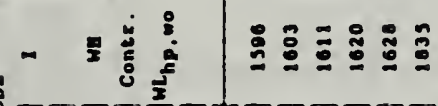

草-D- - 至- - - - - -

×

ม้อ

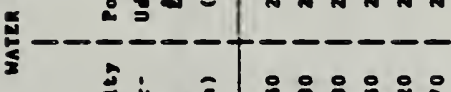

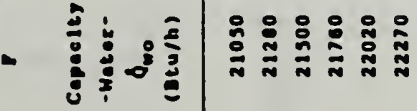

己

范范

$\dot{1}$

营

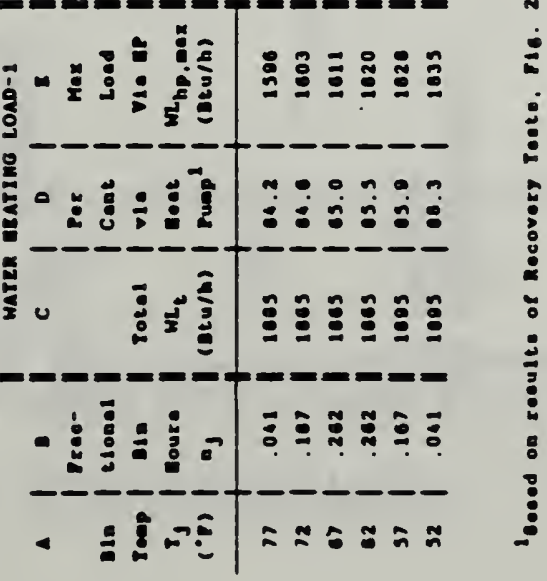




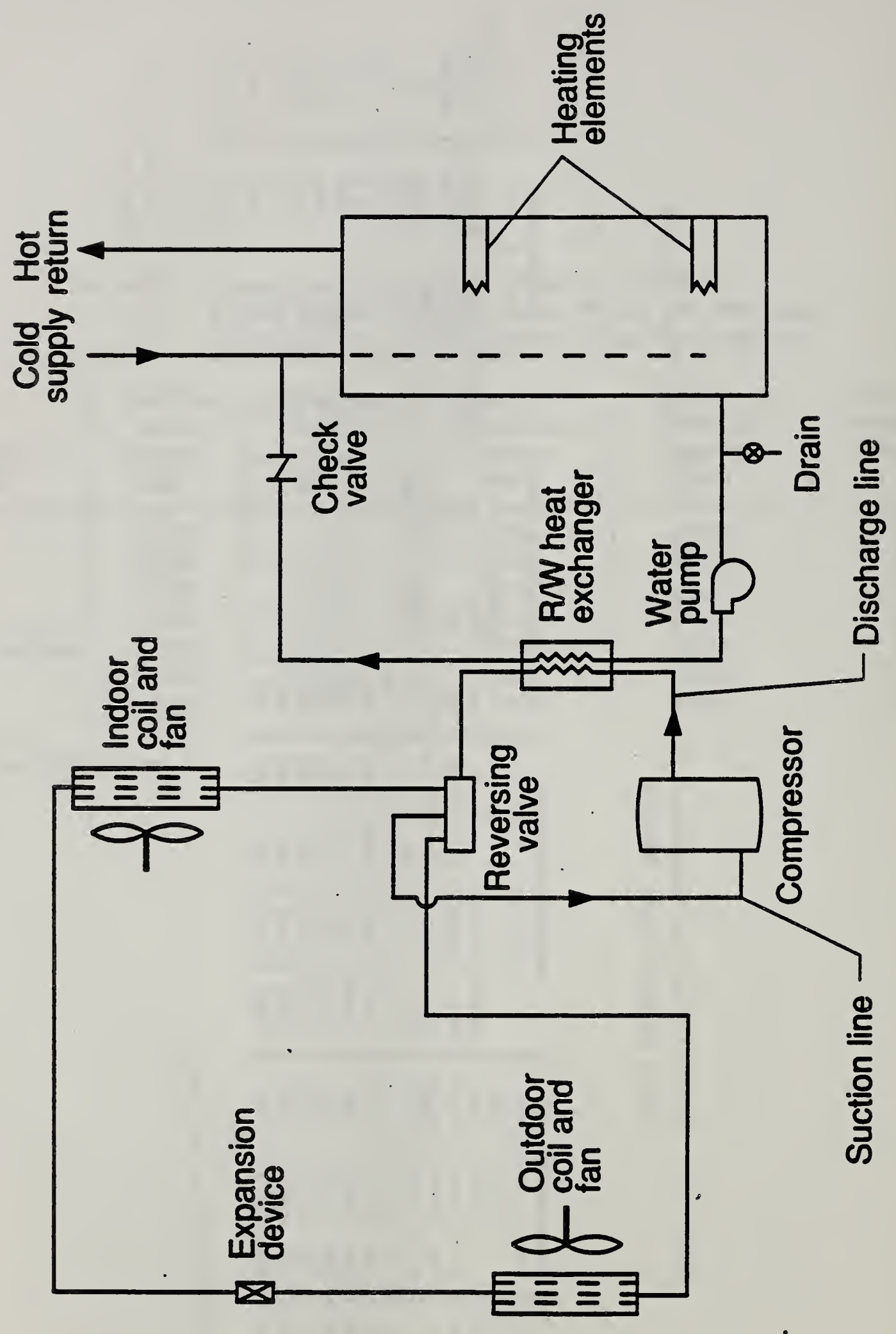

ป⿱艹 


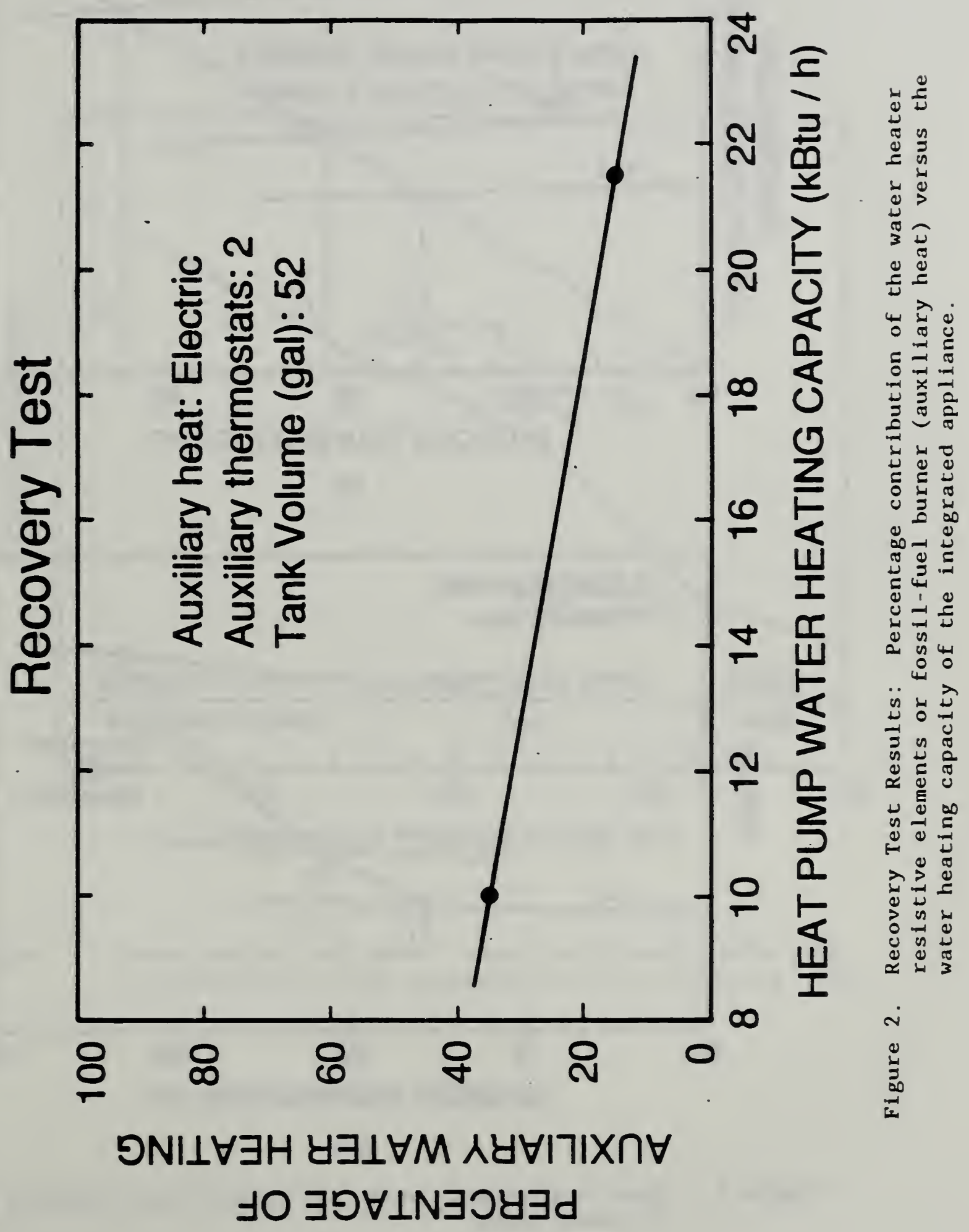




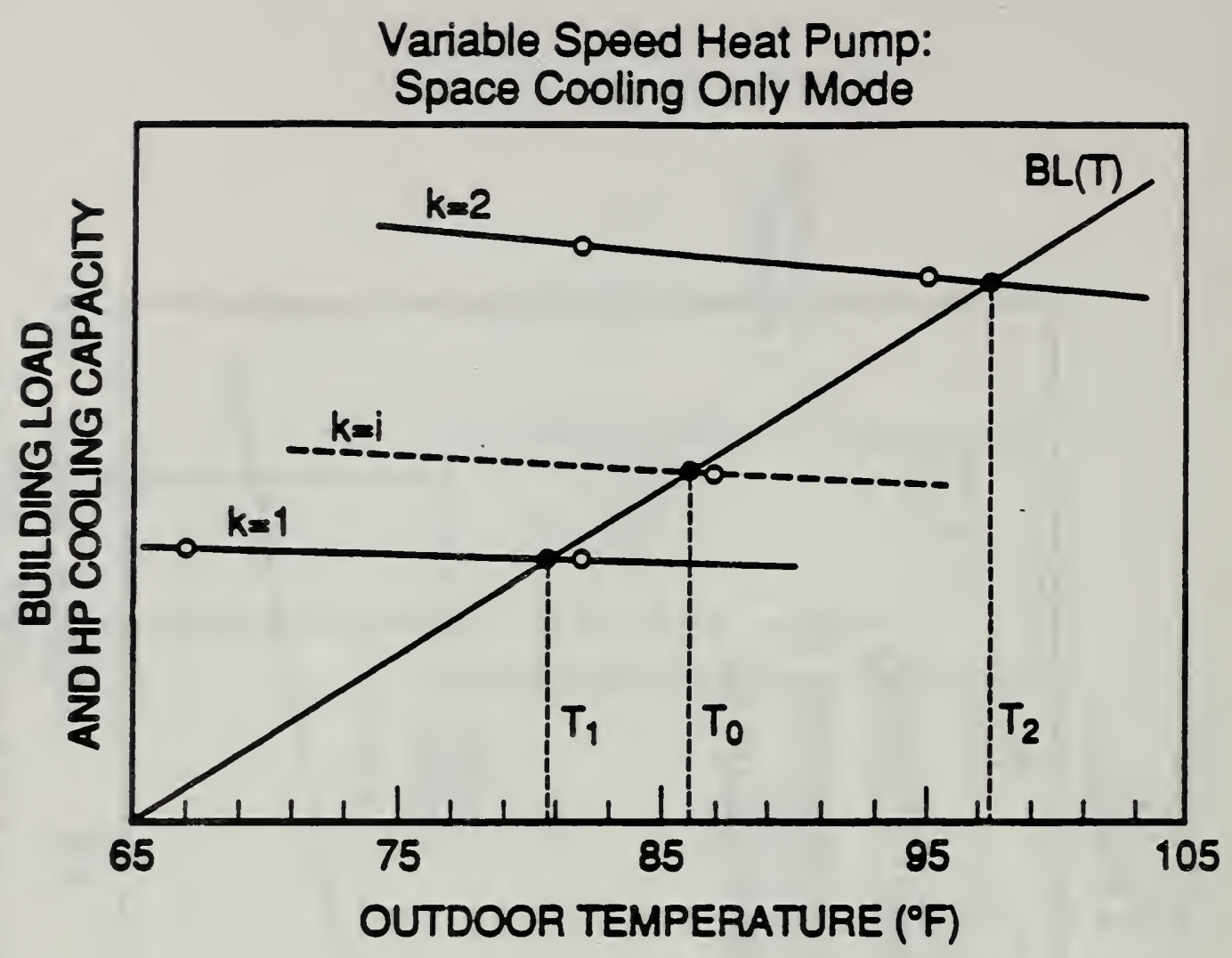

(a)

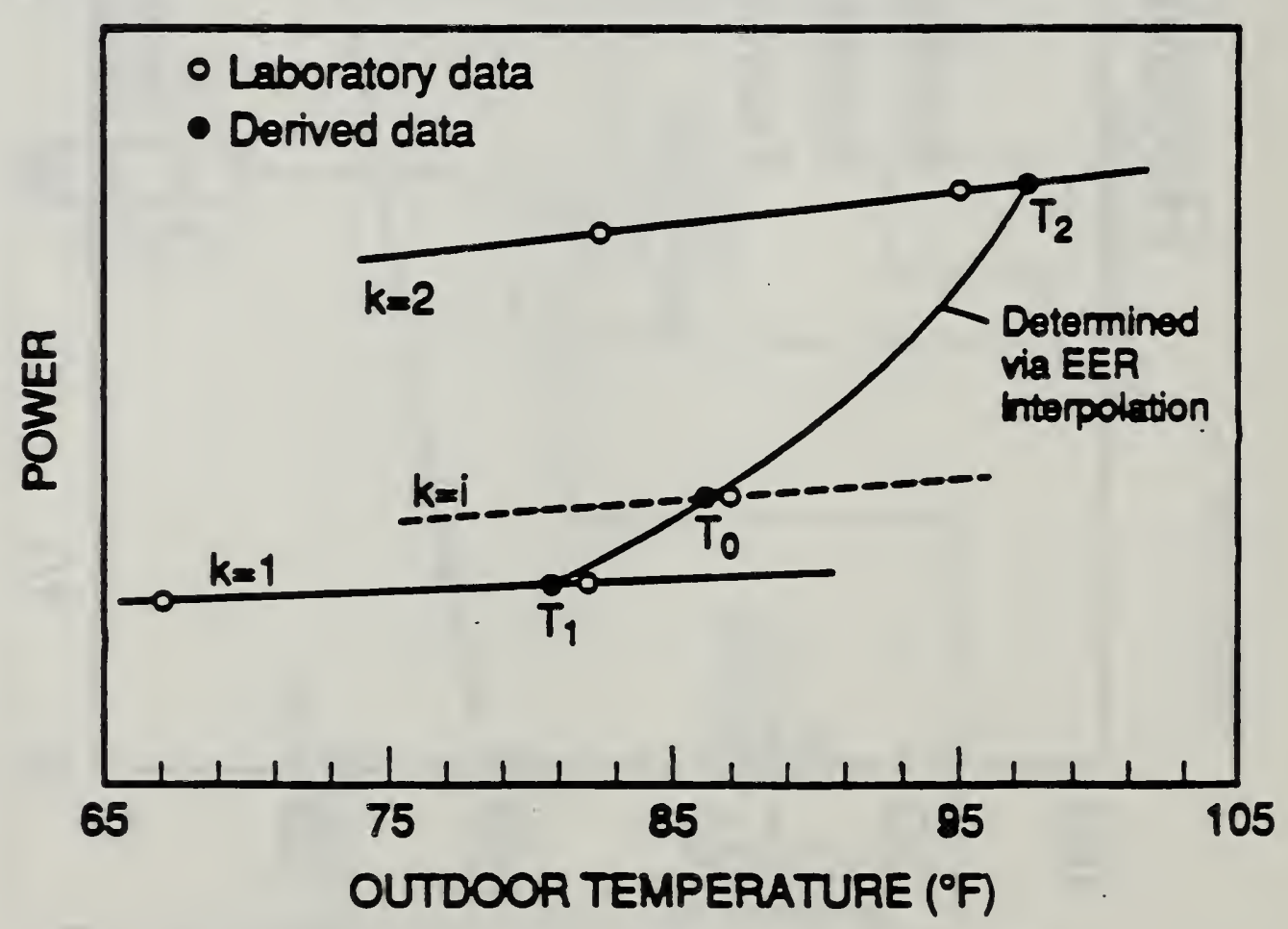

(b)

Figure 3. Space cooling only mode: (a) capacity and building load (b) power usage. 


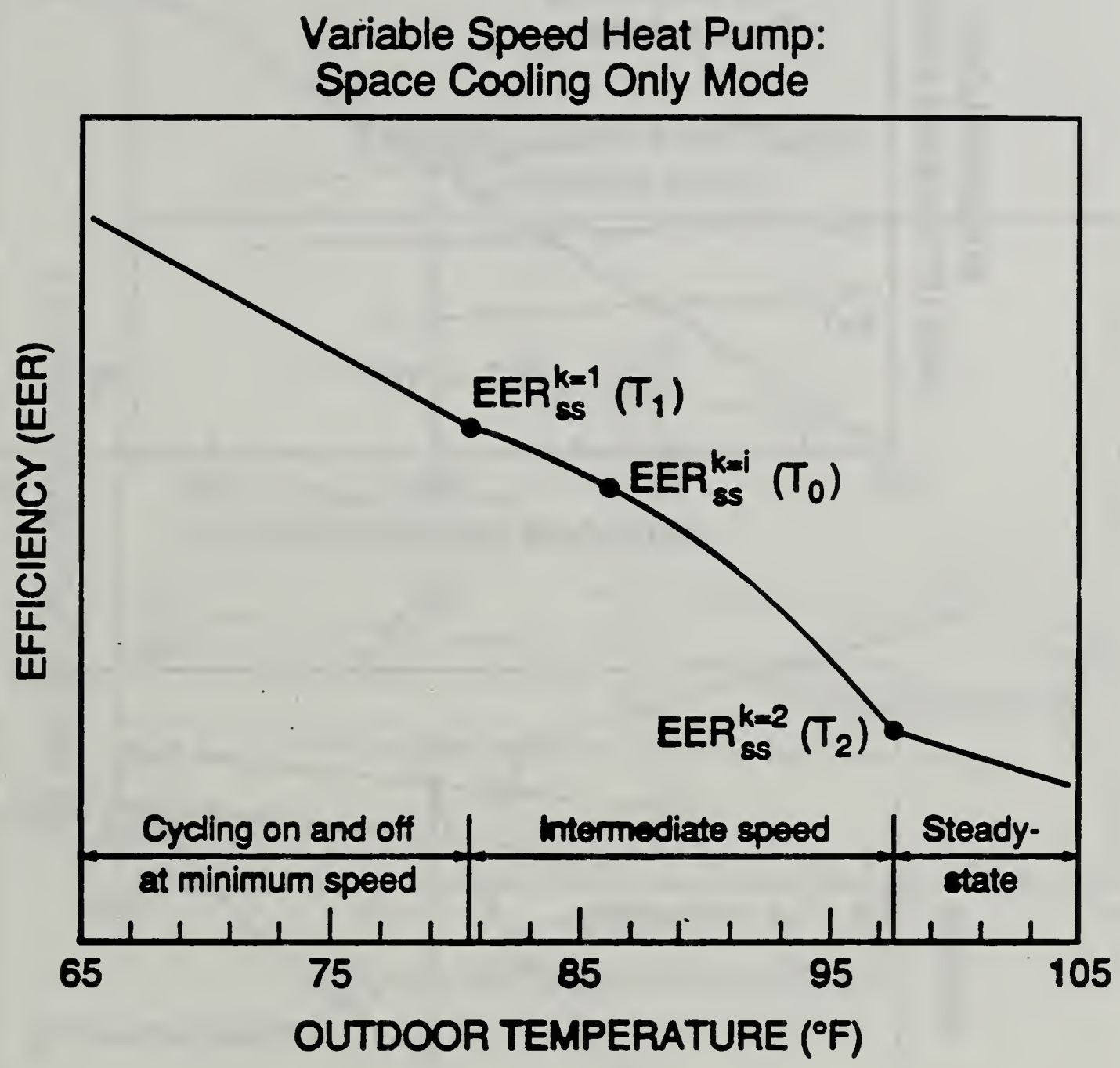

Figure 4. Space cooling only mode: energy efficiency ratio (EER) interpolation for the intermediate-speed operating range. 


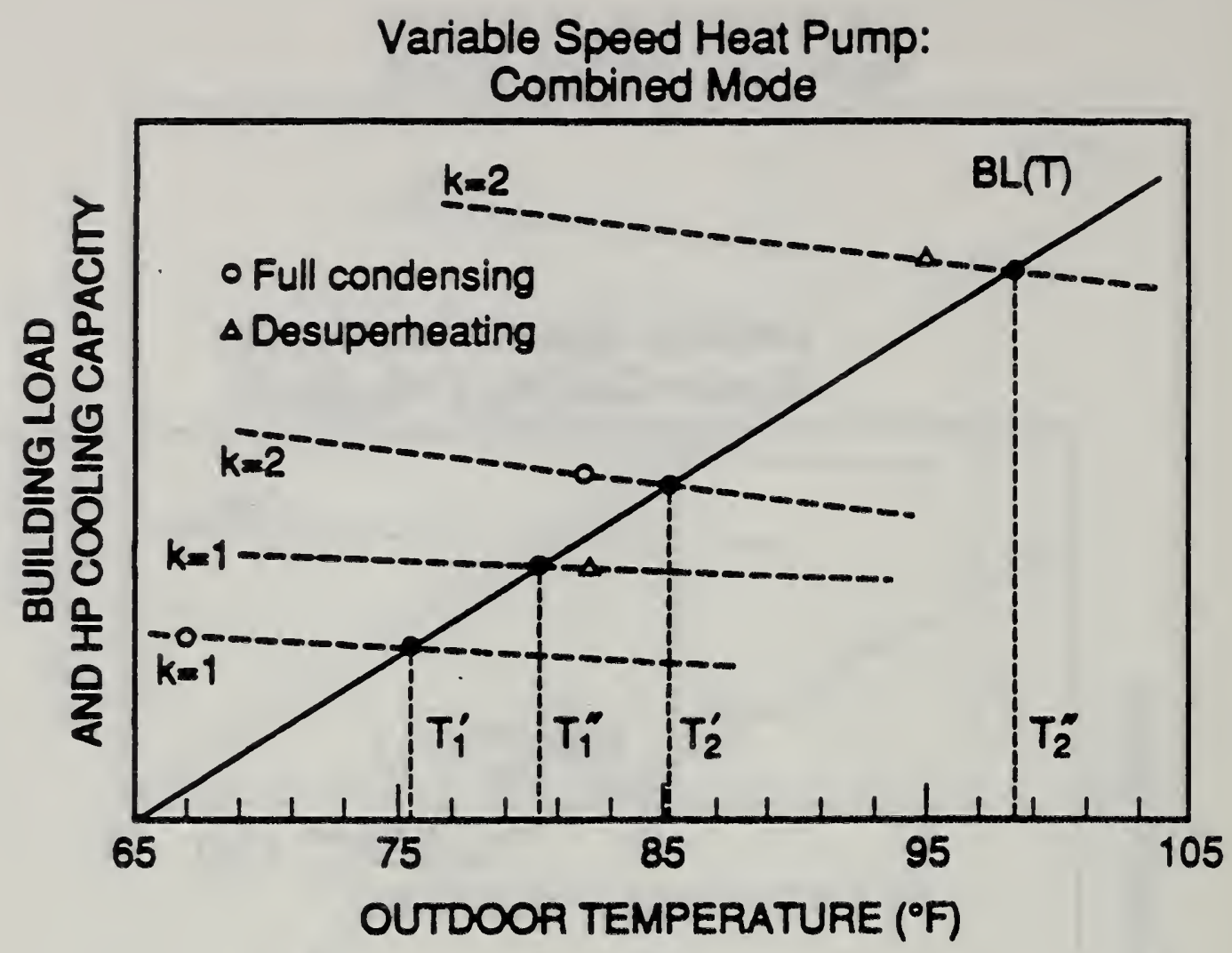

(a)

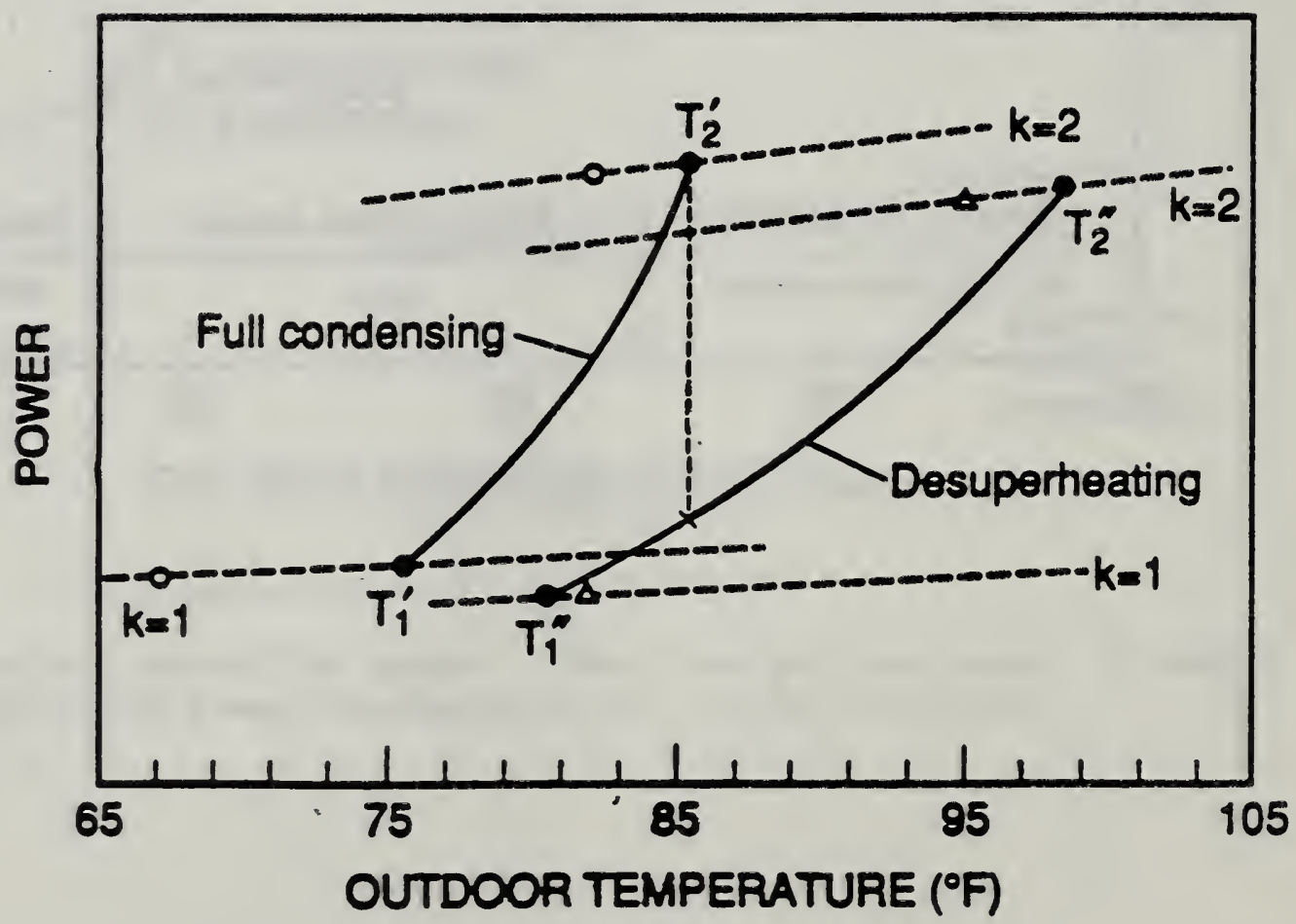

(b)

Figure 5. Combined space cooling and water heating mode: (a) space cooling capacity and building load (b) power usage. 


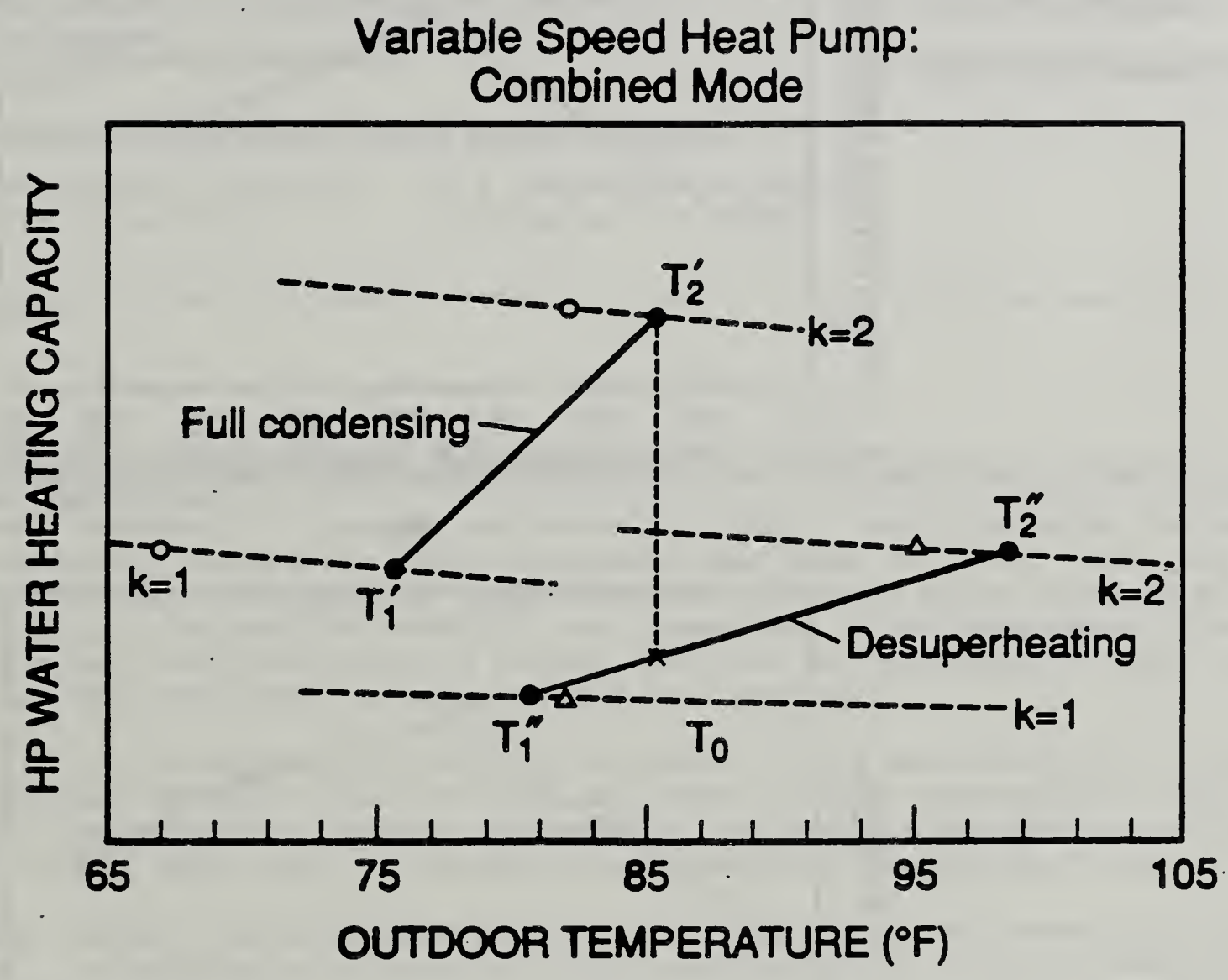

Figure 6. Combined space cooling and water heating mode: water heating capacity of the integrated appliance. 


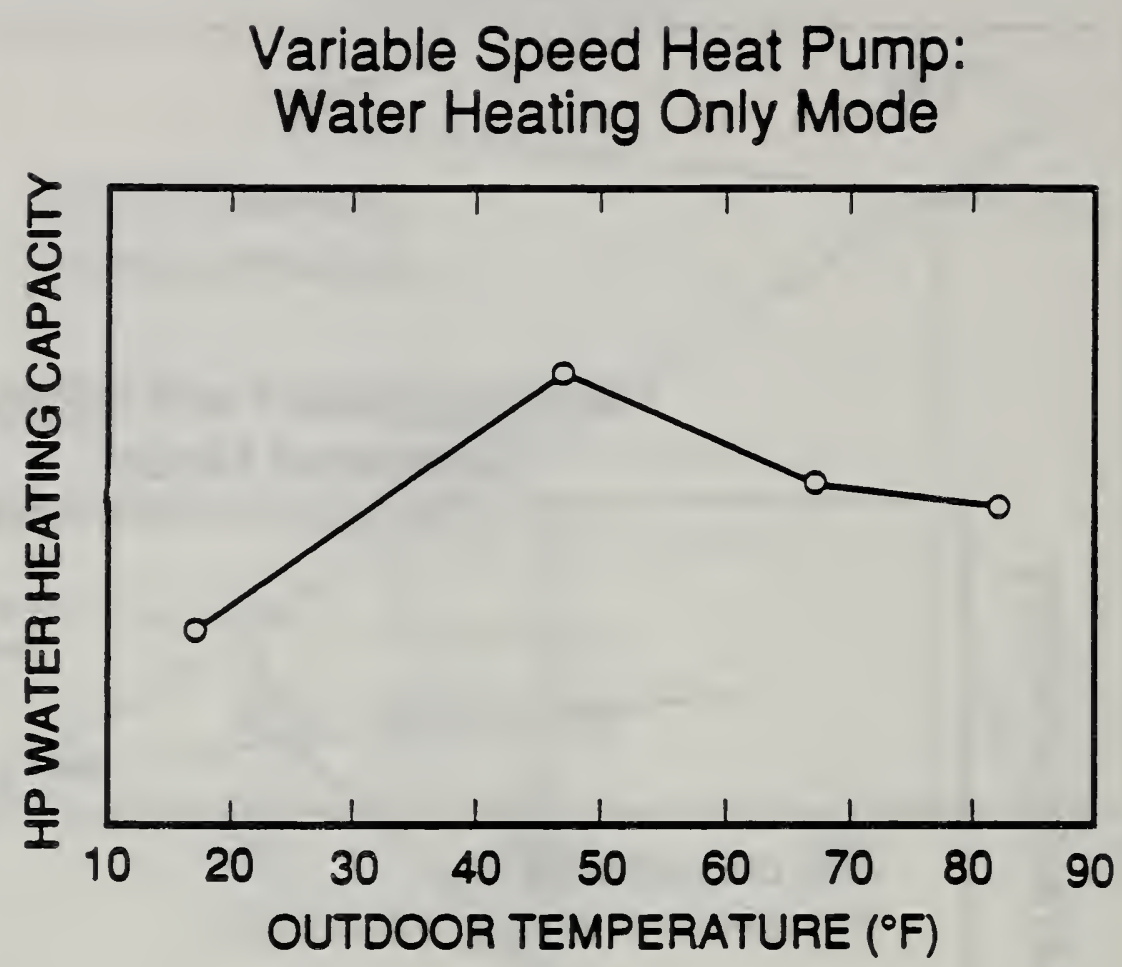

(a)

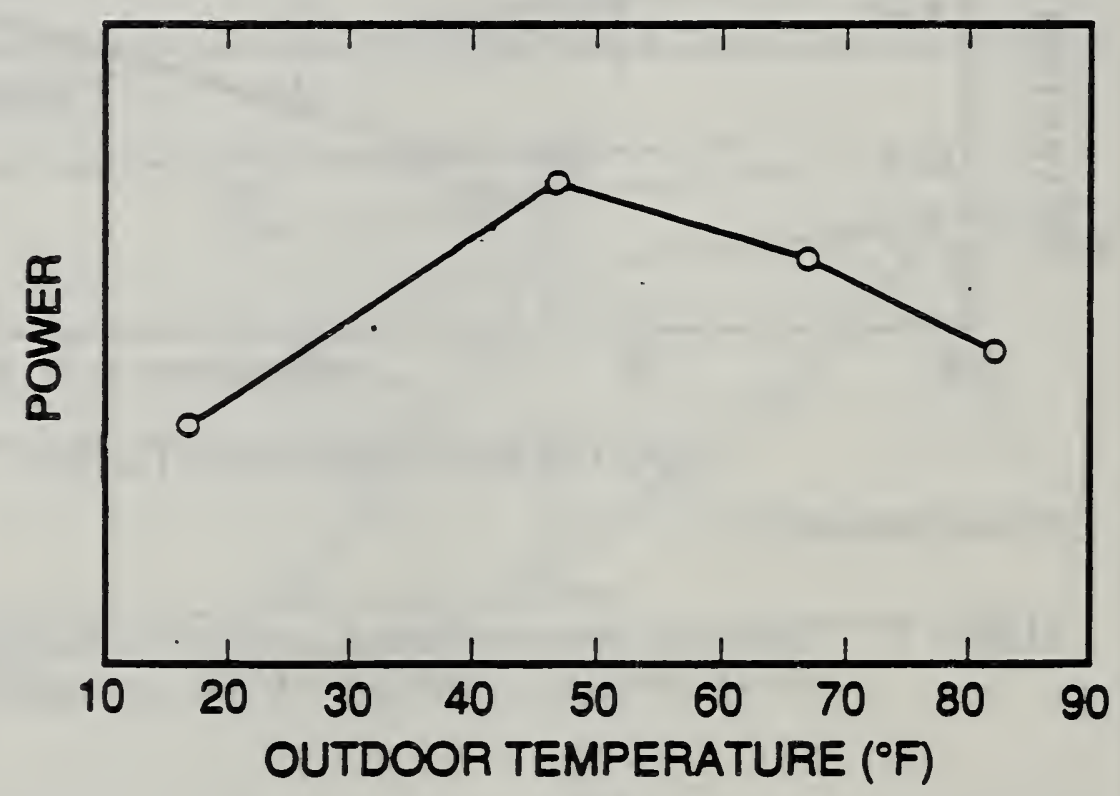

(b)

Figure 7. Water heating only mode: (a) capacity (b) power usage. 


\begin{tabular}{|c|c|c|}
\hline \multirow[t]{3}{*}{\begin{tabular}{|l} 
NIST-114A \\
(REV. 3-89)
\end{tabular}} & \multirow{3}{*}{$\begin{array}{l}\text { U.S. DEPARTMENT OF COMMERCE } \\
\text { NATIONAL INSTITUTE OF STANDARDS AND TECHNOLOGY } \\
\text { BIBLIOGRAPHIC DATA SHEET }\end{array}$} & \begin{tabular}{|l} 
1. PUBUCATION OR REPOAT NUMBER \\
NIST IR $89-4154$ \\
2. PERFORMING OR QANIZATION REPORT NUMBER
\end{tabular} \\
\hline & & \\
\hline & & \\
\hline
\end{tabular}

4. TILEAND SUCTITLE

A Proposed Methodology for Rating Air-Source Heat Pumps That Heat, Cool, and Provide Domestic Water Heating

5. AUTHON(3)

Brian Dougherty

6. PERFORMIMQ ORCAMIZATION (IF JOINT OR OTHER THAN NIST, SEE IMSTRUCTIONS)

U.S. DEPARTMEMT OP COMMERCE

MATHONL INSTITUTE OF STANDARDS AND TECHNOLOQY

cartuEnstura, Mo 20090

7. CONTRACT/GRANT NUMBER

8. TYPE OF REPORT AND PEAIOD COVERED

9. SPONSORING ORQANIZATION MAME AND COMPLETE ADDAESS (STRET, CTT, STATE, ZIA)

Electric Power Research Institute U.S. Department of Energy

Palo Alto, California 94304

Washington, D.C. 20585

10. SUPPLMENTARY NOTES

DOCULEMT DESCNIEES A COMPUTER PROGRAM; SF-18S, FIPS SOFTWARE SUMMUAY, IS ATTACHED.

11. ASTTMCT (A 200-WORD OR LESS FACTUAL SUMMARY OF MOST SIONIFICANT INFOKMATION. FF DOCUMIJT IMCUUDES A SIONIFICANT BIOUOGRAPHY OA ITERATURE SUMVT, MaMTION IT HERE,

At the National Institute of Standards and Technology (NIST), work is on-going to develop a proposed procedure for testing and rating air-source heat pumps that heat, cool, and provide domestic water heating. The family of appliances providing these three functions are referred to here as integrated (or combined) heat pump/water heating appliances. For these appliances, the heat pump contributes to heating the water in a storage-type water heater through the use of a refrigerant-to-potable water heat exchanger.

The work at NIST has centered upon developing a proposed rating methodology for integrated appliances that heat water in a water heating only mode or while simultaneously airconditioning or space heating. Despite the emphasis, the proposed methodology provides a framework for rating other types of integrated heat pump/water heating appliances.

The laboratory testing, the calculation procedure, and the method for reporting performance are described. The testing is an adaption of the laboratory tests conducted when rating conventional heat pumps and water heaters. Seasonal estimates of energy consumption rates are calculated using a bin type approach. Combined performance factors and operating costs are used for reporting performance.

12 KEY WOADS (6 TO 12 ENTRIES; ALPHABETICAL OADEA; CAPTALZE ONLY PROFEA MAMES; AND SEPARATE KEY WORDS OY SEMICOLOMS)

air conditioning, heat pump, integrated appliance, rating methodology, seasonal performance, space heating, water heating.

13. AVALARITY

$\mathrm{X}$ UAUMUTED

FOR OFFICLL DISTRIBUTION. DO NOT RELEASE TO MATOMNL TECHNICAL MMFORMATON SENVCE (NTIS).

ORDER FROM SUPERINTENDENT OF DOCUMENTS, U.S. GOVENMMENT PAINTING OFFICE, WASHIMGTON, DC 20402

ORDER FROM MATIONAL TECHMICAL INFORMATION SERVICE (MTIS), SPRIMGFIED, VA 22161.

14. NUMBER OF PAINTED PAGES

107

15. PAICE

A06

ELECTRONIC FORM 

